\title{
An essay on railway track bed failure issues, analysis and remedy
}

\author{
S M Nazmuz Sakib \\ Graduate of BSc in Business Studies \\ School of Business And Trade \\ Pilatusstrasse 6003, 6003 Luzern, Switzerland \\ sakibpedia@gmail.com \\ Student of Department of Law \\ Dhaka International University \\ House \# 4, Road \# 1, Block - F, Dhaka 1213 \\ sakibpedia@students.diu.ac \\ Student of BEcon in Environmental and Resource Economics \\ Dhaka School of Economics \\ 4/C Eskaton Garden Rd, Ramna, Dhaka 1000, Bangladesh. \\ sakib.bee5@dsce.edu.bd
}

\begin{abstract}
The polymer cures as it enters the ballast, forming a three-dimensional geo-composite reinforcing cage. Although there will be some adherence to the ballast in dry conditions, the polymer's primary job is to construct this reinforcing cage. Polymer penetration is controlled by altering the rheology of the polymer. The method is also said to include a built-in safety system, with the track reverting to a ballast state in the event of a polymer or geo-composite failure. Many of the sites were considered unmaintainable before the polymer was put. The design method was utilized to forecast track behaviour before and after treatment, allowing the most appropriate polymer rheology, polymer distribution, and loading levels to be designed in order to achieve optimum performance and confirm that the procedure worked. This method can be utilized to tackle these types of long-standing problems by displaying actual polymer application profiles at a typical important location.
\end{abstract}

Keywords: Railway, Track bed, Track bed failure, Railway track, Track bed failure remedy 


\section{INTRODUCTION}

\subsection{General introduction of the United Kingdom rolling stock}

The first British public railway debuted in 1825, making it one of the world's oldest railway systems. It is the world's sixth busiest railway, with an annual increase in passenger traffic. Deteriorating infrastructure has caused various safety and operational difficulties in the past, necessitating costly replacement and repairs. Furthermore, massive modernisation projects must be performed to cope with increased capacity, maintain train infrastructure safety, and assure efficiency. As a result, the railway infrastructure in the United Kingdom is under enormous pressure to keep it safe and cost-effective, as well as to ensure that repairs, replacements, and any rail projects achieve those goals. In the first part the United Kingdom a short rolling stock statistic is produced. Therefore, the data is showing what a great impact railway is playing in everyone's life on daily basis. The United Kingdom's (UK) national rail network is a highly valued asset with a big physical presence that many people use daily. It serves over 2,500 different stations and encompasses around 16,000 kilometres of railway routes. The network delivers over 1.7 billion passenger journeys and 17 billion tonne kilometres of freight each year. The sector directly employs around 240,000 people (William, 2021). UK's railway ran over 21,000 services on an average day - a third more than 20 years ago. The number of passengers and goods transported by train has increased dramatically in the UK. Figure 1 statistic shows that between 1950 and 2020, the number of passenger journeys on UK national rail increased by more than $74 \%$.

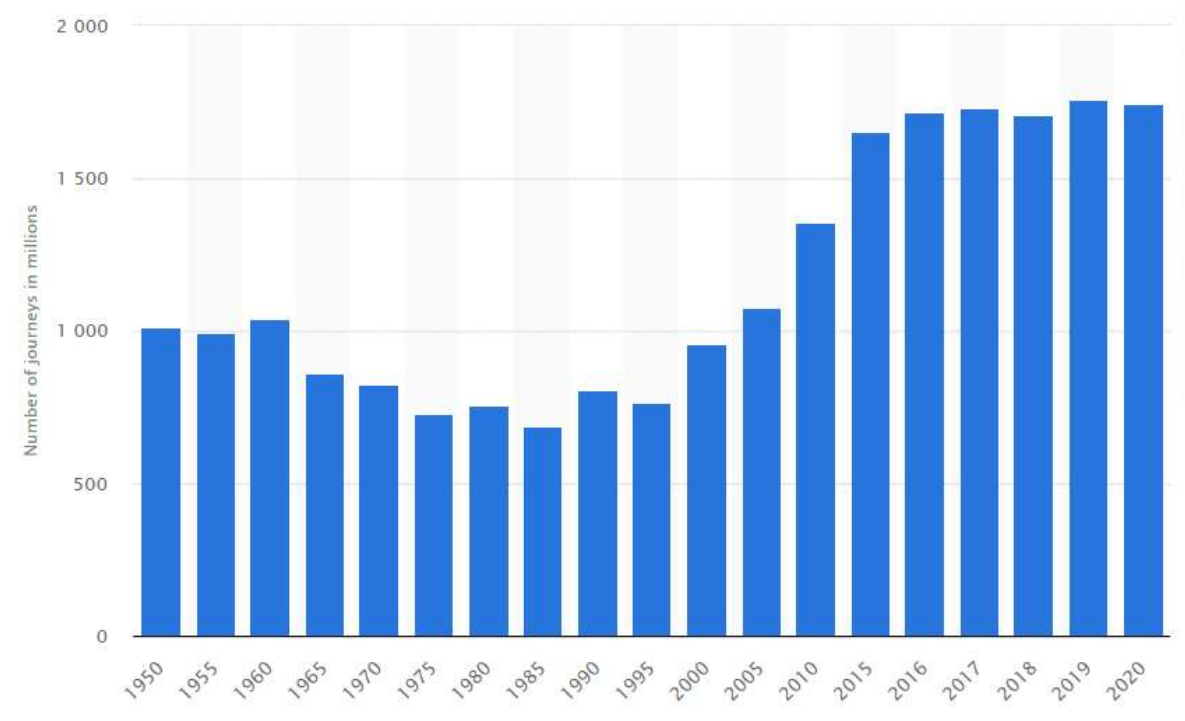

Figure 1 from 1950 to 2020, total historical national rail passenger travels in the United Kingdom (Statista, 2020)

Rolling stock have a number of advantages over other modes of transportation, including great reliability, capability, and safety. Rail freight emits $76 \%$ less carbon than road freight, 
and with a freight train carrying the equivalent of 110 lorries, an increase in rail freight will not only decrease Britain's carbon footprint but also dramatically reduce traffic congestion. The rail freight market has been transformed over past quarter century, from largely moving coal and steel to moving construction materials, containers and food supplies between ports and businesses across the country. And finally, they have played a crucial role in keeping food and medical supplies moving during pandemic and the freight sector will be key to building back economic recovery across the country.

\subsection{Aim}

Nonetheless, whether is the increased usage of railway transportation or any other causes brings with it plenty of issues. In these circumstances' maintenance costs rise in parallel. However, as the infrastructure is used more frequently, very limited access to the railway maintenance works are provided. Therefore, an effective maintenance regime it is crucial, to identify track problems at early stage and to avoid unplanned/ emergency works or catastrophic results. Therefore, the aim of this research is to identify the most widespread UK's track bed problems, their causes, and effective remedies for these conditions.

\subsection{Objectives}

A list of research objectives is provided below. These aims demonstrate how this dissertation aim will be achieved.

- Introduction to railway track bed;

- Maintenance regime of track bed;

- Types of track bed failure;

- The most common methods for track bed remediation;

- Discussion on 3 track bed failure cases;

- Conclusions and recommendations.

Structure of the dissertation

The following are explained the chapters of this report. Chapter 2 contains literature review from related studies including latest research studies has been done to for solving ballast movement and fouling issues in the track bed. Chapter 3 covers the track bed construction specifications according to the latest standards and current maintenance practices are being used to maintain UK's railway track bed. Following that, Chapter 4 discusses the most typical issues that UK track beds face, as well as the possible sources of these issues. Next, Chapter 5 discusses three case studies illustrating problems in the track bed, as well as what are the most common practice is being in comparison with a new technology to evaluate the optimization problem. Finally, Chapter 5 includes conclusions along with a comparison what other potential solutions could be used to treat similar issues arising in the track bed, and further research. 


\section{LITERATURE REVIEW (not finished)}

Railway infrastructure is made up of various assets such as railway tracks, electrical system, signalling devices, switches, and stations. The entire system consists of interconnected assets that work together. Therefore, ballast track bed is one of the most important components, and it is utilised as a crucial component of railway track systems' stability. Unfortunately, it requires very effective maintenance regime plan in place, as well as competent and experienced people to make effective and efficient decisions.

What are the gaps in the research? What I'm trying to find out. Important to find out where authors disagree about one or other aspect. Why they disagree? Evaluate it. To prove that I know who the experts in the field are. Suggest where research is going. Make sure that topics that are suggested in the title are covered. (ABLESIM)

General at the beginning and the narrower categories, focus, hypothesis. At the end need to say that: based on this information here is what I want to look at that there is a gap in the research.

Some of the researches on the effects of fouling material and water content on ballast performance have been briefly explained in the following paragraphs:

- Budiono et al. in 2004, Huang et al. 2009 and Giannakos in 2010 showed that fine fouling material particles adversely affect the strength, stiffness, and life cycle of the track (Budiono et al., 2004, Giannakos, 2010, Huang et al., 2009).

- In 2010 Konstantinos Giannakos presented an equation to relate the fouling percentage to the ballast hardness derived from the analysis of the laboratory test result. He reported that in a constant loading cycles the breakdown fouling particles increase by decrease in the hardness of ballast (Giannakos, 2010).

- A review of the literature has shown that fouling and moisture content have significant effects on deformation and index geotechnical properties of the ballast. In addition, ballast is an important part of the railroad track which must perform different functions. An increase in fouling percentage and moisture content will decrease the workability of the ballast and takes the ballast to the high-risk situation and safety problems. In another perspective, the review also reveals the significant effects of moisture content and fouling percentages on the electromagnetic properties of the ballast.

- Many researchers have shown that gradation of the ballast has significant effects

- on the mechanical properties of ballast, such as increase in plastic strain of the ballast by

- changing the broadly graded ballast to uniformly graded ballast, increase in friction angle 
- by adding large particles (Klugar, 2014), change in shear strength by change in particles sizes (Chen, 1948, Holtz \& Gibbs, 1956, Koerner, 1970, Leslie, 1963, Marachi et al., 1900)

- but Selig and Waters in 1994 reported that this effect of particle size on strength is unclear.

\subsection{Introduction to railway track bed}

This chapter deals with the components that ballasted track bed is containing. As well, the most common principles of the track bed construction will be explained. Also, what function the track bed is providing.

The classic railway track bed basically consists of a flat framework made up of rails and sleepers which is supported on ballast. The ballast bed rests on a sub- ballast layer which forms the transition layer to the formation. Figure 1 show the construction principle of the classic track structure. The rail and sleepers are connected by fastenings. These components and other structures such as switches and crossings are all considered as part of the track.

On ballasted track, vertical and lateral alignment must be maintained, and each track must perform its required functions under any circumstances (Indraratna and Salim, 2005).

The main function of the track bed is to provide stability and to reduce the pressure caused by train passage.

Unfortunately, ballast is the main source of rail track deterioration. Figure 1.2 shows a typical profile of the relative contribution of substructure layers on track settlement with a good subgrade soil foundation as a comparator (Selig and Waters, 1994). Ballast generally contributes much more to the track settlement than either the sub- ballast or subgrade.

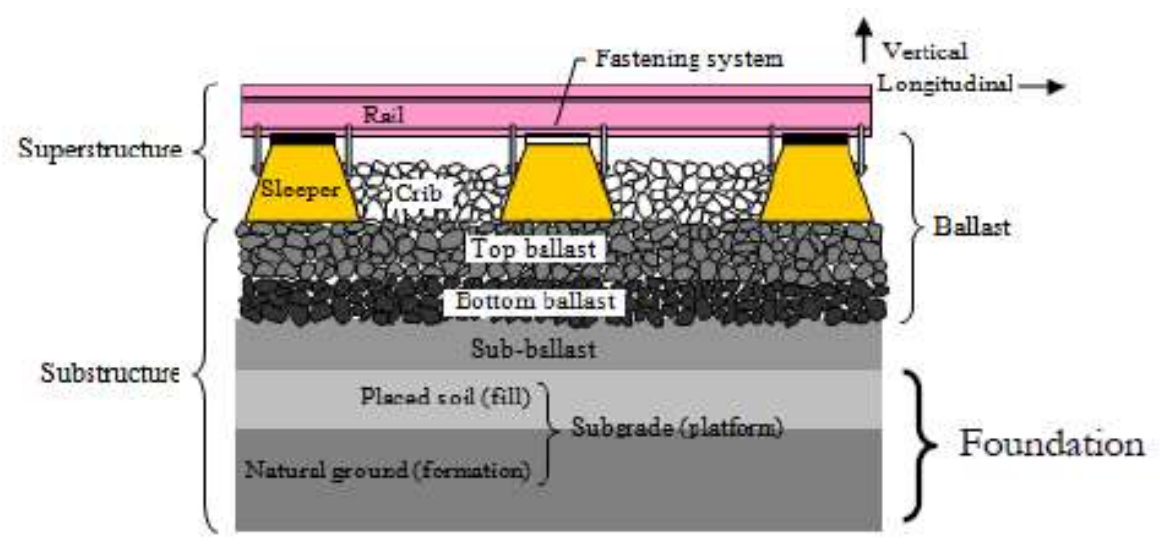

Figure 2. Track structure components (after Selig and Waters, 1994)

Apart from attenuating the high pressure at the sleeper/ ballast interface, providing a free draining medium and support the rail sleeper system, ballast also (Selig and Waters, 1994): 
1. Provides track resilience and absorbs airborne noise.

2. Facilitates maintenance surfacing and lining operations to adjust track geometry through rearranging ballast articles by tamping.

3. Inhibits vegetation growth.

4. Provides a dry supporting medium for the service of sleeper.

\subsection{Ballast fouling}

The most common causes of ballast fouling have been well investigated in the literature. In general, the deterioration of ballast aggregate and the penetration of tiny particles into this porous media describe the contamination mechanism of railway ballast course (Qian et al., 2018). According to Qian, fouling has a negative impact on railroad track performance due to inadequate drainage and the resulting technical issues, which include mud pumping, excessive settlement, and lower bearing capacity, among others.

Selig and Waters (1994) discussed the numerous factors that influenced ballast degradation in the track bed:

- Deterioration of mechanical particles during construction and maintenance activity, as well as traffic loads;

- Changes in the environment cause chemical breakdown and mechanical deterioration;

- Fine particle movement from the surface and underlying layers;

- Freight traffic spills;

- Sleepers degradation.

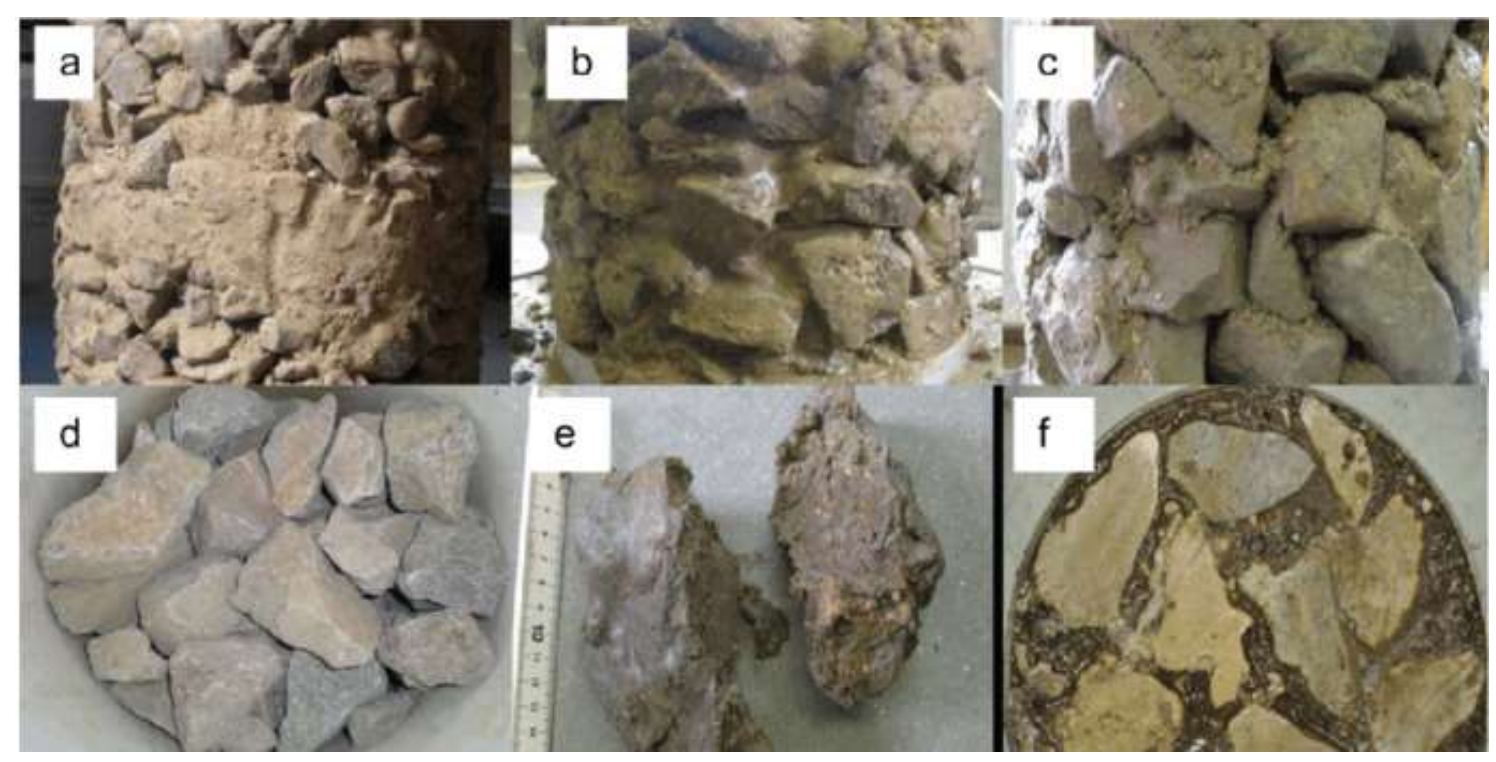

Figure 3. Layered fouling mixture (a), highly fouled ballast (b), moderately fouled ballast (c), clean ballast (d), ballast particle coated by fouling (e), and cross section of fouled ballast (f) from the specimens of large - scale cyclic triaxial test (Ebrahimi et al. 2012). 
Fouling materials have different sources which can be divided into five categories (Selig \& Waters, 1994):

1. Ballast break down.

2. Infiltration from ballast.

3. Sleeper (Tie) wear.

4. Infiltration from underlying granular layers.

5. Subgrade infiltration.

\subsection{Railway drainage}

Fouled ballast has been a subject of many researches and as a result of these research, it is clear that a lack of an appropriate drainage system may be the root of the majority of the problems in the track bed, particularly when UK's railway is typically 100 years old. It is a vital factor in ensuring the effectiveness and long- life of ballast. In this chapter will be explained importance of the railway drainage system and maintenance regime for it is effectiveness.

One of the key factors affecting track performance is effective drainage system. Figure 4 is showing that the drainage system must be able to cope with water from all sources. $80 \%$ of the water falling on track flows along the interface of the ballast subgrade (Cope, 1993).

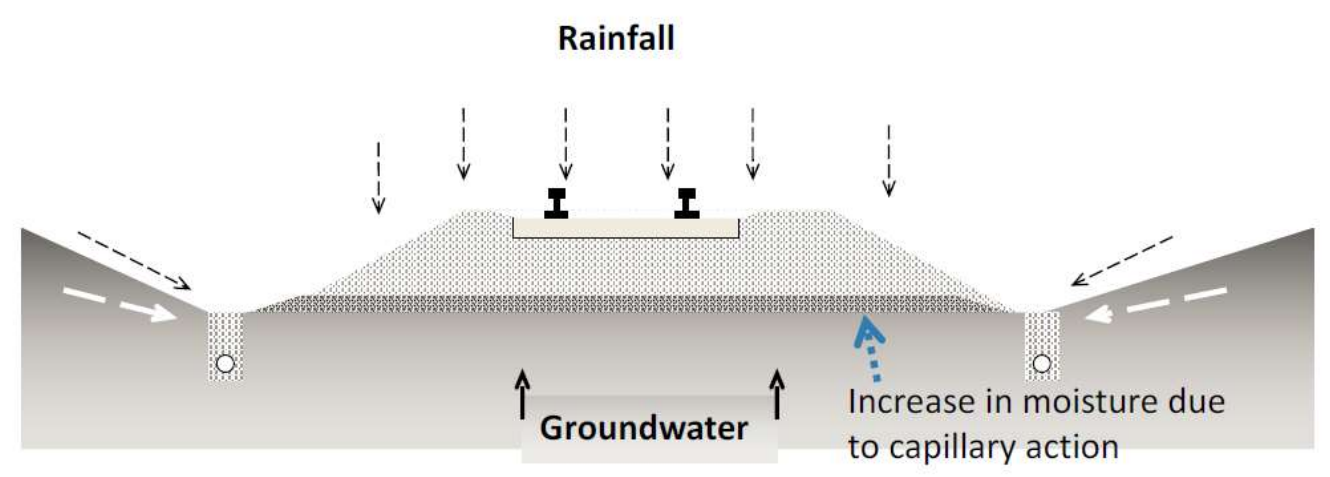

Figure 4. Railway drainage performance (Ghataora 2017).

Water must be carefully channelled away from vulnerable track assets to an outfall in a railway drainage system. Every component of the system must perform properly to be effective. Drainage systems must be well-maintained to function correctly, such as:

- Check track drainage is running.

- Inspect that debris/spoil has not been deposited on cess restricting run- off.

- Regular ditches maintenance inspection from vegetation overgrown or/and debris blockage. 
- Check that catchpits are not damaged.

Inadequate railway track drainage affects the type of failure. In addition to loss of line and level poor drainage can lead to formation of wet spots (GC/RT5014 2011). Excessive water in the upper portion of a railway track foundation can cause softening and, as a result, a variety of track failures. The following are the failure mechanisms of fine subgrade soils that are aggravated by the presence of water:

1. Progressive subgrade shear failure

Due to cyclic over-stressing, progressive shear failure develops at the subgrade surface as the soil is shared and remoulded. The surface of the subgrade gradually squeezes outward and upward, following the path of least resistance, in this form of failure (Figure 5).

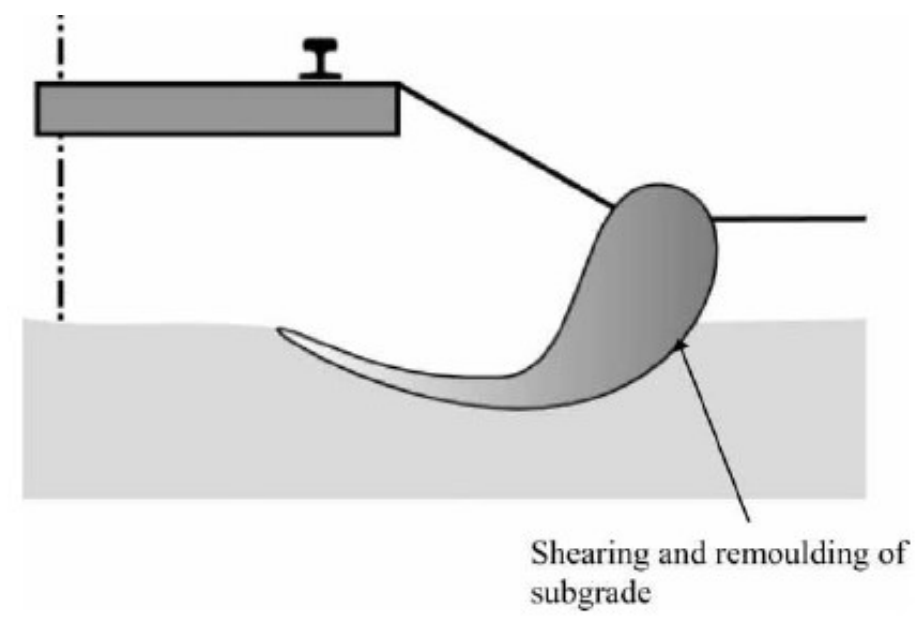

Figure 5. Subgrade progressive shear failure (Esveld, 2001)

2. Excessive Plastic Deformation in the Subgrade

An excessive rate of settlement due to plastic deformation frequently leads in the formation of a ballast pocket, as seen in Figure 6. The vertical component of shear deformation generated by gradual compaction of the subgrade layer as a result of repetitive loading forms the ballast pocket (Ghataora 2006).

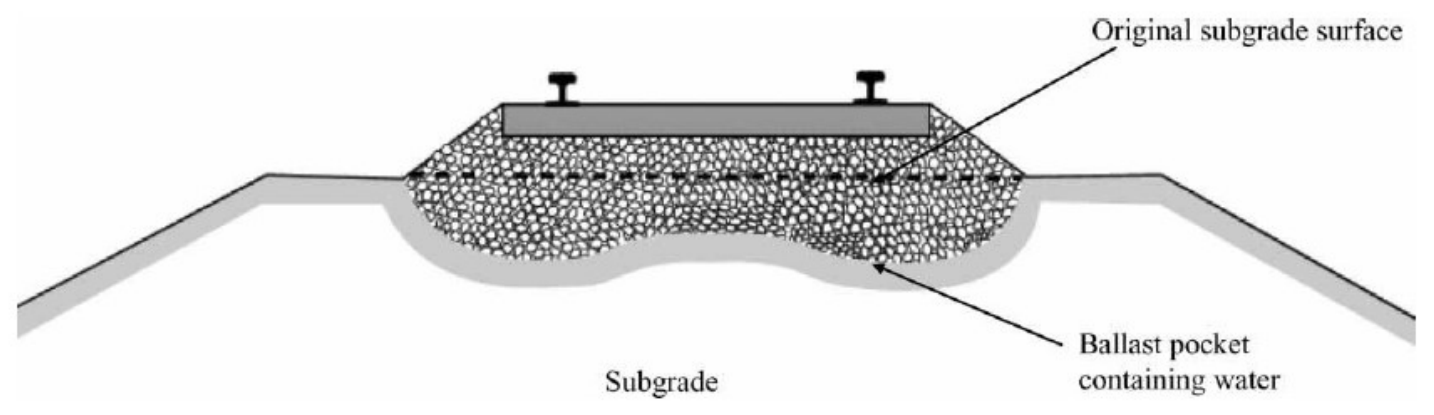

Figure 2. Excessive subgrade plastic deformation (Ghataora, 2006) 
NR/L3/CIV/005 Railway drainage systems manual; NR/L3/CIV/003/3A and NR/L3/CIV/003/3B.

Drainage is regularly inspected and cleared as often as necessary to keep it working properly. Blocked drainage is a common cause of proof track geometry, clogged ballast, increased track maintenance and shortened track asset life. To conclude this chapter all researches agrees that stability of the track and earthworks depends on drainage systematic maintenance such as:

- Maintaining constant low water content

- Reduce groundwater level at acceptable depth.

2.4 Track stiffness

Several studies have been conducted to establish the ideal global track stiffness value, ensuring that the track is neither too stiff to generate contact fatigue and ballast attrition, nor too soft to create rail bending fatigue and ballast settlement.

Too stiff

Due to higher dynamic loads, track beds that are overly stiff might cause faster deterioration of the track and its components. In these circumstances, soft pads and resiliently placed sleepers are two options for reducing stiffness.

Reasons

Ballast onto a stiff structure, such as a concrete bridge deck, a concrete tunnel invert, or bedrock directly. Modern earthwork fills can also be quite stiff.

Ballast onto a stiff structure, such as a concrete bridge deck, a concrete tunnel invert, or bedrock directly. Modern earthwork fills can also be quite stiff.

Remediation

Install softer rail pads, under sleeper pads, ballast mats over structures, sand blanket, and/or greater depth of ballast and sub-ballast to reduce support rigidity.

Too variable

At the railway-bridge, railway-tunnel, and bridge-tunnel sections, the stiffness varies quickly, hence transition zones must be established. Furthermore, as track geometric irregularity deteriorates, track support becomes inconsistent.

https://link.springer.com/article/10.1007/s40534-016-0104-8

Problem 
The degree of stiffness is far too varied. Insufficient support rigidity transition onto or off a substructure, or from slab to ballasted track. Rail and component damage, ballast attrition, severe voiding beneath the sleeper, and loss of the ballast shoulder

Remediation

Reduce stiffness on the hard construction by using softer rail pads, under sleeper pads, and the ballast mast selectively. In addition, to balance track stiffness in extreme conditions, utilise micro-piles and other reinforcement techniques.

Track stiffness optimisation

Several studies have been conducted to identify the optimal global track stiffness value, so that the track is neither too stiff to induce contact fatigue and ballast attrition, nor too soft to induce rail bending fatigues and ballast settlement.

Pita et al. (2004) investigated the relationship between track stiffness and total cost (track construction and maintenance) and found that the optimum worldwide track stiffness, with the lowest total asset cost, is between $70 \mathrm{Kn} / \mathrm{mm}$ and $80 \mathrm{Kn} / \mathrm{mm}$. However, later research has found that the ideal global track stiffness varies depending on line characteristics (Puzavace et al, 2012).

Track stiffness isn't well defined, although it can be considered of as the amount of elastic deflection of the rail when a wheel load is applied. When the rails are under traffic, it's critical to know how much they deflect elastically under an applied wheel load. Track stiffness is determined by the elements of track components such as the rail, rail pad, sleepers (under sleeper pads), ballast, sub ballast, and formation.

All these components are very important when trying to achieve optimum stiffness. All specifications for rail components and material are very clearly specified in the standards, such as specifications for size of aggregates, as well as construction standards has to be maintained at all times, also specifications for drainage, separate layers for sand blankets and etc. And unfortunately, everything is stopping there.

Values of typical formation stiffness

The stiffness of a formation is not linear or elastic, but it does rise as applied stress rise. Some of the problems there with settlement permanent deflection and looking at the rail pads is very stiff around pad but even there it is a limited amount you come up to the overall formation stiffness. Actual measurements in the UK have shown formation stiffness values ranging from 10 to $200 \mathrm{MN} / \mathrm{m} /$ sleeper end. And as we see very a big range is here.

The formation stiffness is the most variable, least understood, and hardest to adjust of all the track components. If we are going to try and change formation it is a lot of work, particularly in June, construction, but also as a maintenance activity afterwards, so it is very important part of the system, but perhaps less well understood and controlled. 
Formation Stiffness Variability - why we have different thickness and formations (ALL IN COLOR TO BE CHANGED)

- $\quad$ Formation materials and thickness

- $\quad$ Soil types

- Underlying geology

- Climate

- $\quad$ Moisture content

- Drainage

- Compaction

- $\quad$ Settlement

- $\quad$ Structures

- Transitions

Plot here shows the darker blue areas of the geology which is more inclined to high level of shrink or swell as moisture content there the clay type areas, see a big blue movement in the track just because of the water content in there so quite complex. If you look at typical sort of better, where is a railway on brought and mainline in that situation, we have got 6 or 7 different geological formations there on that stuck around way out of the top not deeply when we won't keep it nice and flat and level throughout the various conditions changing climate you can see there anything from London Clay to Hastings Sand, so there is nothing like consistent formation. 


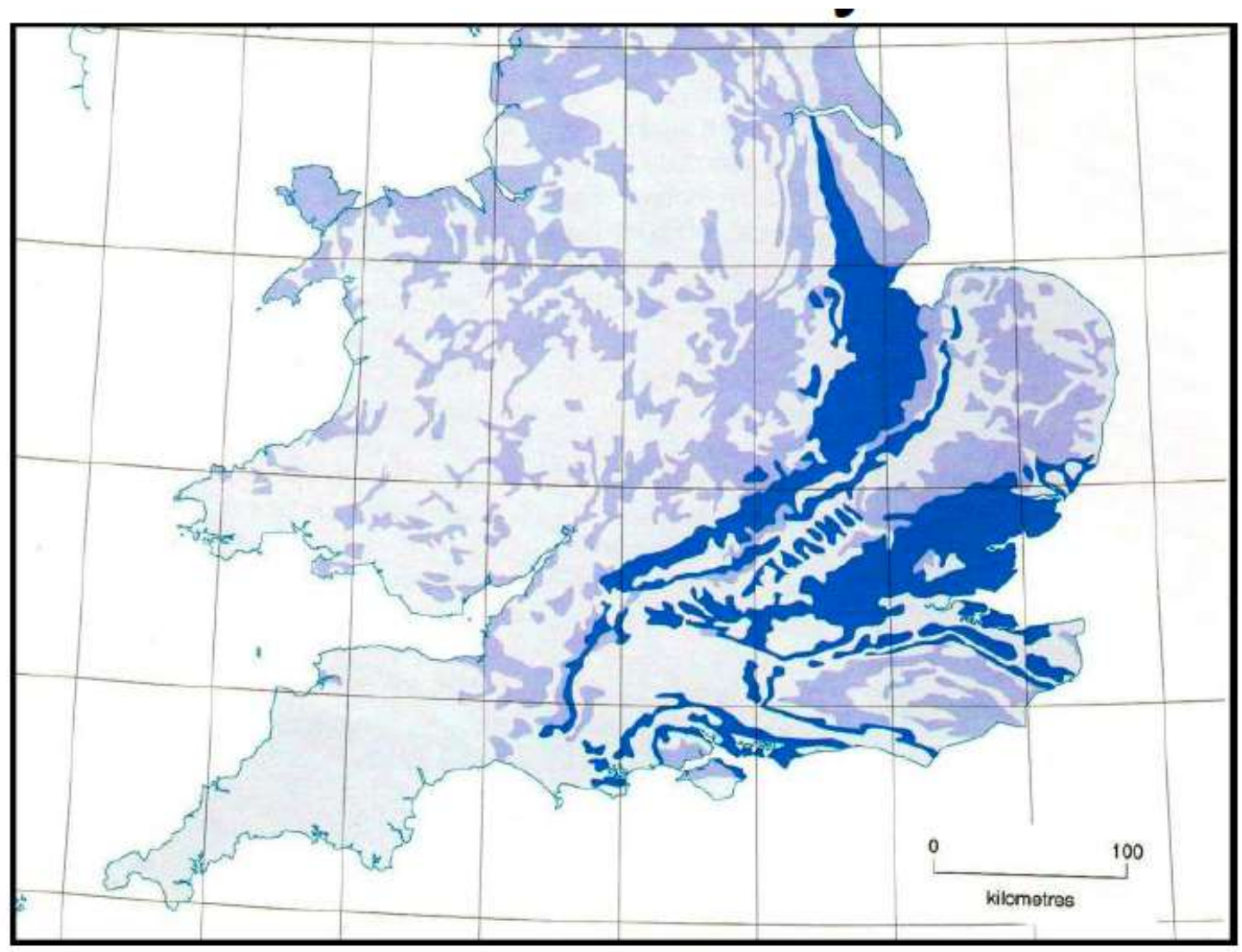

The British Geological Survey provided this map of probable swell-shrink in clay soils.

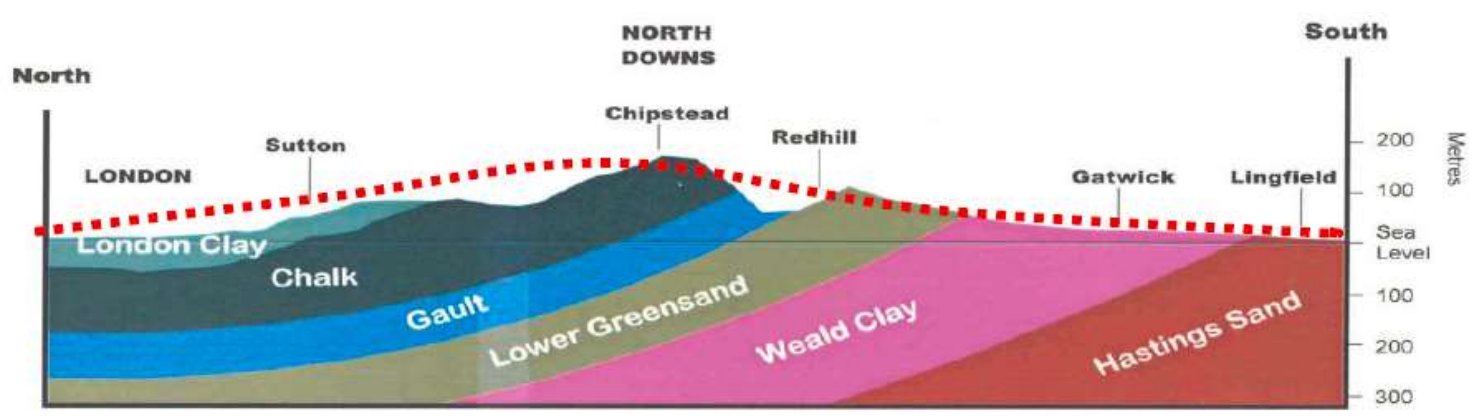

There other things worrying about from the track engineers' point of view it is a localized or variable settlement, really causes the problems. If it all moves together that is not so much of an issue but from the diagram below there are just a lines traces films touched on some of those with the rolling standard deviations, but you can see the range of deterioration where the track quality is very good deterioration tends to be lower, track quality is worse in this example where as it actually a problem with a low formation as it starts to deteriorate the energy starts to increase the deterioration starts to increase and will end up with some quite significant problems with geometry trying to remove that roughness which builds over the time and a lot of activities that trap carry out we will try to cure or correct some of those failures. 
A number of features can significantly increase the rail load:

- Sharp variations in track stiffness, such as wet places, changes in construction, under bridges, and so on, can raise the dynamic stress in the rail by up to three times that of old track; some circumstances may be even more intense, but the rail is subjected to a significant transformation.

- At lower speeds or when the difference in track stiffness is less destructive than a short-wet spot in a high stiffness track, this dynamic stress is less severe.

- Straight, level, and supported on a consistent stiffness structure, the ideal track has the lowest rail stresses.

- Excessive loads may not break the rail in most circumstances, but they can cause minor fatigue cracks that grow under normal stress.

- These could be existing stress raisers like fishplates joints, bolt holes, corrosion pitting, and inherent rail manufacturer flaws, among other things.

- Rail life is determined by the loads it is exposed to and the amount of time it is exposed to these stresses.

- Repairing defects quickly and with reduced intervention levels reduces cumulative damage and extends component life. 


\subsection{Mud pumping causes}

Fines migration, also known as mud pumping, causes the ballast to become contaminated, reducing its load-carrying capacity and finally leading to track geometry loss and the formation of damp spots. As a result of the loss of track shape, ride quality may deteriorate, speed restrictions may be imposed, and maintenance costs may rise. The problem is ubiquitous in the UK; for example, Ghataora (2009) discovered an average of 5 damp areas per mile of track. Figure 5 is showing that in addition to loss of line and level, poor drainage system can lead to formation wet spots, which is contaminated by slurry which has risen from the ballast.

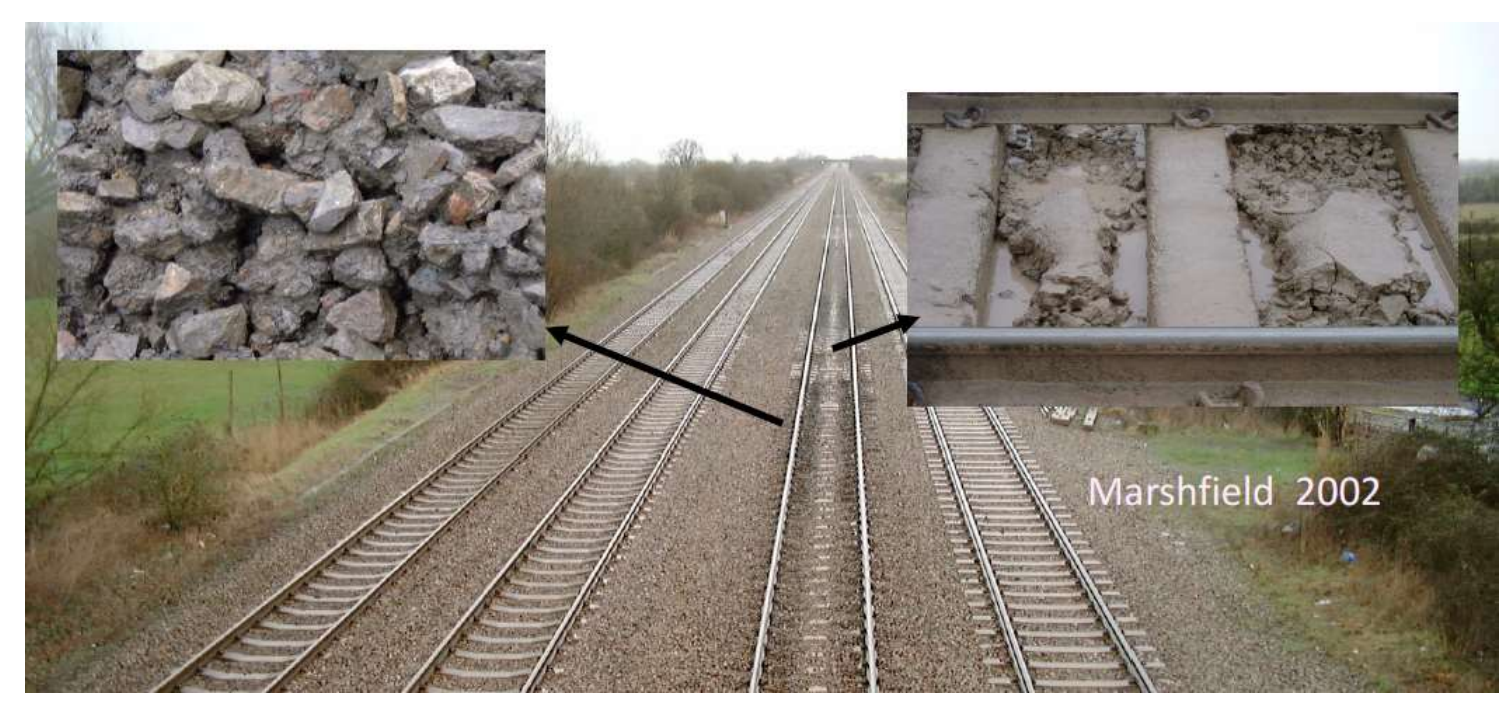

Figure 5. Wet spot: track surface is contaminated by slurry (Ghataora, 2009)

The cause of the problem is unknown, though it has been related to aggregates pressing down on the subgrade surface, generating local stress concentrations and, as a result, subgrade softening soil forming slurry. The degradation of the subgrade by the ballast under dynamic train loads in the presence of water has also been linked to the development of slurry (Ghataora, 2009). Fine material such as clay are the main source of ballast fouling and this leads to mud pumping. Several researchers (Trinh et al., 2012; Cui et al., 2014; Duong et al., 2013) have investigated that in the behaviour of a zone consisting of ballast mixed with material from the subgrade which they refer to as the "interlayer". Duong et al. (2013) suggest that the interlayer is formed primarily by the penetration of ballast into the subgrade. This occurs in older railways built prior to the introduction of engineered sub-ballast layers, usually consisting of graded sand to separate the ballast and the sub-grade. Aside from the basic types of track subgrade failure listed above, there are a fewer common type of failure as well (Wang et al. 2014).

- Liquefaction: Repeated loading, saturated silt, and fine sand create liquefaction, which results in a considerable displacement. 
- Static soil stress increased due to embankment weight and saturated fine-grained soils, resulting in consolidation settlement.

- Frost action (heave and softening): changes in moisture content and highly plastic soils cause the track surface to heave and soften.

- Slope erosion occurs when surface and subsurface water erodes the soil.

- Soil collapse is the result of water inundating loose soil deposits, causing ground settling.

In some cases, geometry deterioration appears due to settlement or formation failure. In these circumstances track can be subject to rapid and unpredictable geometry deterioration. To limit the effect of geometry faults and poor ride quality from embankment settlement or rapid sub- grade failure, it may be necessary to apply an emergency speed restriction and additional monitoring until corrective action is complete. Remedial action requirements and timescales are described in Table 4.

\subsection{Maintenance}

In order to construct and maintain rail lines effectively, it is necessary to understand the behaviour of the track bed and its underlying embankment infrastructure. As a result, maintenance costs can be reduced while track safety is improved by knowing the causes of all issues in the track bed, as well as behaviour of the railway embankment. Ballast can be maintained in a variety of ways, including tamping, ballast cleaning, stone blowing, and partial or full track renewal.

Ballast can effectively carry the weights when trains roll over and remain still, however ballast quality deteriorates over time as a result of frequent track use. As a result of the degradation, track misalignment occurs and track performance declines such as uncomfortable passenger journey due to differential in settlement, speed restrictions with the result of train delays, and even potential derailment. If the level of degradation passes specified limits, the safety of railway operations may be risked. Ballast must be maintained to ensure that its performance meets technical and safety criterial in order to avoid such unanticipated occurrences.

\subsubsection{Key focus areas for maintenance}

The key principle is that risk from the track assets has to be understood so that appropriate controls can be selected and applied. Risk may be related to safety, performance, cost or shortened asset life. The Track Maintenance Engineer and Section Manager (Track) identify risk from the track assets, assess those risks and take action to control them. This is a continuous process that has to be followed by using the results of inspections and the full range of track asset information that is available. 
The track system is inspected and measured at intervals in line with the construction of the track, the speed and tonnage of traffic. Minimum frequencies are based on these criteria. Additional inspections, actions or shorter timescales may be required to control the risks caused by poor track condition, faults that are deteriorating rapidly, location or features (such as $\mathrm{S} \& \mathrm{C}$, curves or joints), limited access, the effects of weather or disturbance that reduces track stability.

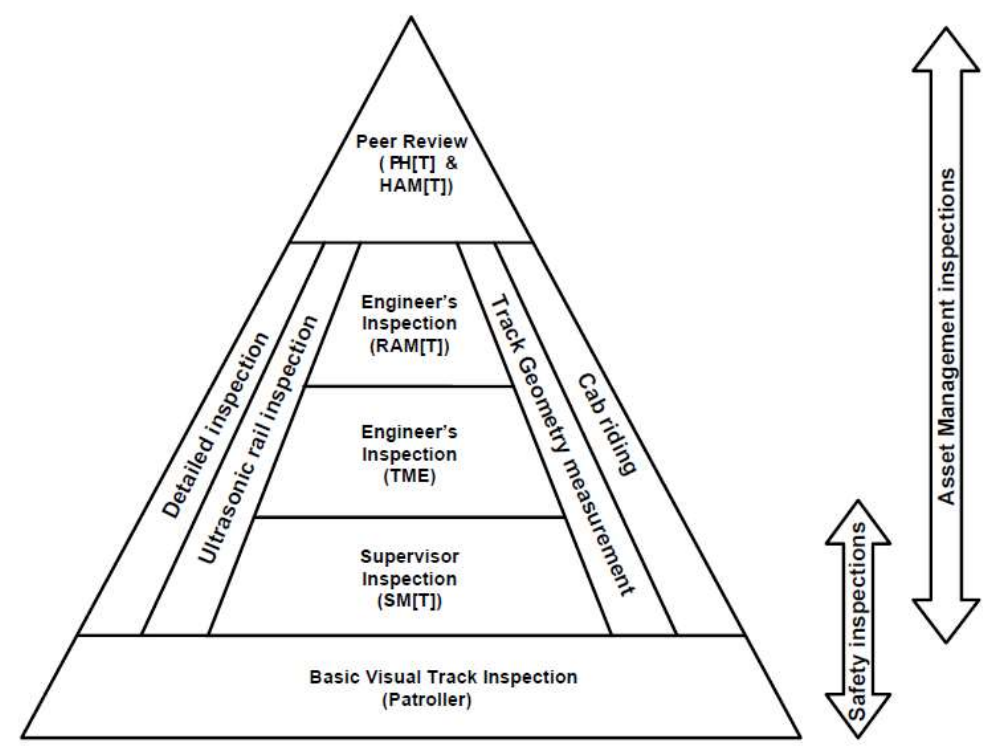

Figure 1. Hierarchy of track inspection

The Figure 1. is showing hierarchy of track inspection which, it starts from basic visual track inspection identify any immediate or short-term actions required. Then Section Manager track inspections include measurements of gauge, cross - level and other features, where identifies work to be prioritised, planned and carried out; identifies items to be proposed for renewal or refurbishment; checks that completed work and other inspections are effective. Identify locations with poor ride quality that require further inspection and work Cab riding inspections are undertaken. Therefore, Detailed Inspections Check the condition of specific types of track infrastructure, where measurements are taken and recorded. Ultrasonic rail inspections identify and measure surface and internal defects in rails. One of the most crucial is Track geometry measurement identifies and measures track geometry faults and track geometry faults and track geometry quality. The track inspection process includes an assessment of dynamic movement of the traffic under traffic. This may be achieved by the track geometry measurement and by looking for the symptoms of movement on site, such as voiding, gauge widening, etc. Direct observation of the track under traffic is also required, which might need special access arrangements. The root causes of faults are identified so that repairs are effective, and the faults do not come back. If these two aims are not achieved, the value of inspections is lost. Routine track inspections on their own might not identify root causes. Faults are repaired before they affect the safe performance of the track. If the track is 
not safe for traffic, either a speed restriction is applied, or the line is blocked until the necessary repairs have been carried out.

Track can be obstructed by fallen trees, livestock and objects placed on the line by vandal. There are also separate standards and specifications of work to be taken to manage track in hot and cold weather due to precautions prior to the start of the cold or hot weather.

Visual inspections are carried out at intervals related to the Track Category of the line, which is obtained from the speed of traffic and equivalent annual tonnage using that line. The Track Category Matrix is shown in Figure 2, taking account of any significant changes to the speed or tonnage of traffic that occur.

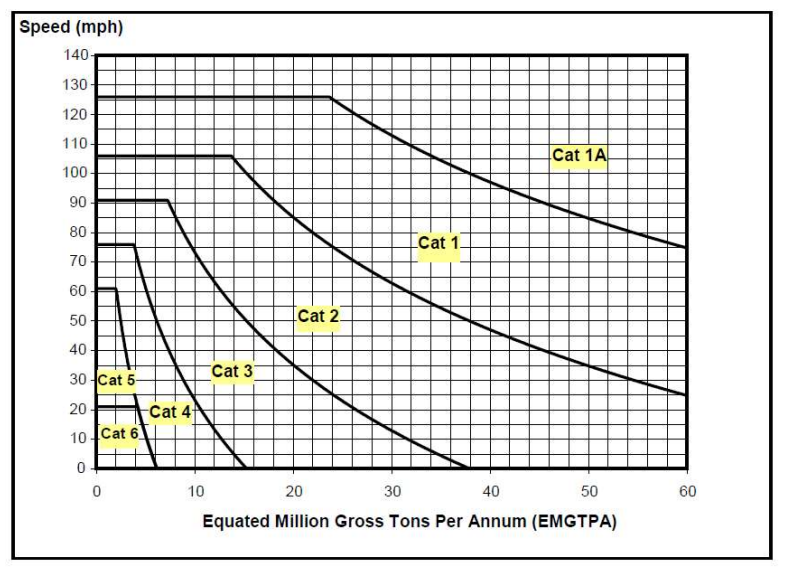

Figure 2. The Track Category Matrix

Undertake basic visual inspections to the minimum frequencies shown in Table 1, where asset condition or traffic changes may indicate that an increase or decrease in the inspection frequency is required.

\begin{tabular}{|c|c|c|c|c|c|c|c|c|}
\hline \multirow[b]{2}{*}{ Activity } & \multirow[b]{2}{*}{ Qualifier } & \multicolumn{7}{|c|}{ Track Category } \\
\hline & & $1 \mathrm{~A}$ & 1 & 2 & 3 & 4 & 5 & 6 \\
\hline $\begin{array}{l}\text { Basic visual inspection of } \\
\text { plain line jointed track }\end{array}$ & & $\mathrm{N} / \mathrm{A}$ & $\begin{array}{c}\text { Twice per } \\
\text { week }\end{array}$ & $\begin{array}{c}\text { Twice per } \\
\text { week }\end{array}$ & $\begin{array}{l}\text { Once per } \\
\text { week }\end{array}$ & $\begin{array}{l}\text { Once per } \\
\text { week }\end{array}$ & $\begin{array}{l}\text { Once per } \\
2 \text { weeks }\end{array}$ & $\begin{array}{l}\text { Once per } \\
2 \text { weeks }\end{array}$ \\
\hline $\begin{array}{l}\text { Basic visual inspection of } \\
\text { plain line CWR }\end{array}$ & $\begin{array}{l}\text { Flat bottom rail on concrete or } \\
\text { steel sleepers }{ }^{1} \text { with pandrol, } \\
\text { SHC or vossloh fastenings. }\end{array}$ & $\begin{array}{l}\text { Once per } \\
2 \text { weeks }\end{array}$ & $\begin{array}{l}\text { Once per } \\
2 \text { weeks }\end{array}$ & $\begin{array}{l}\text { Once per } \\
2 \text { weeks }\end{array}$ & $\begin{array}{l}\text { Once per } \\
4 \text { weeks }\end{array}$ & $\begin{array}{l}\text { Once per } \\
4 \text { weeks }\end{array}$ & $\begin{array}{l}\text { Once per } \\
8 \text { weeks }\end{array}$ & $\begin{array}{l}\text { Once per } \\
8 \text { weeks }\end{array}$ \\
\hline $\begin{array}{l}\text { Basic visual inspection of } \\
\text { plain line CWR }\end{array}$ & All other types of construction ${ }^{2}$. & $\begin{array}{l}\text { Once per } \\
\text { week }\end{array}$ & $\begin{array}{l}\text { Once per } \\
\text { week }\end{array}$ & $\begin{array}{l}\text { Once per } \\
\text { week }\end{array}$ & $\begin{array}{l}\text { Once per } \\
2 \text { weeks }\end{array}$ & $\begin{array}{l}\text { Once per } \\
2 \text { weeks }\end{array}$ & $\begin{array}{l}\text { Once per } \\
4 \text { weeks }\end{array}$ & $\begin{array}{l}\text { Once per } \\
4 \text { weeks }\end{array}$ \\
\hline $\begin{array}{l}\text { Basic visual inspection of } \\
\text { strengthened S\&C }\end{array}$ & $\begin{array}{l}\text { Fully welded shallow depth } \\
\text { switches on concrete bearers }\end{array}$ & $\begin{array}{l}\text { Once per } \\
2 \text { weeks }\end{array}$ & $\begin{array}{l}\text { Once per } \\
2 \text { weeks }\end{array}$ & $\begin{array}{l}\text { Once per } \\
2 \text { weeks }\end{array}$ & $\begin{array}{l}\text { Once per } \\
2 \text { weeks }\end{array}$ & $\begin{array}{l}\text { Once per } \\
2 \text { weeks }\end{array}$ & $\begin{array}{l}\text { Once per } \\
4 \text { weeks }\end{array}$ & $\begin{array}{l}\text { Once per } \\
4 \text { weeks }\end{array}$ \\
\hline $\begin{array}{l}\text { Basic visual inspection of } \\
\text { strengthened S\&C }\end{array}$ & All other types & $\begin{array}{l}\text { Once per } \\
\text { week }\end{array}$ & $\begin{array}{l}\text { Once per } \\
\text { week }\end{array}$ & $\begin{array}{l}\text { Once per } \\
\text { week }\end{array}$ & $\begin{array}{l}\text { Once per } \\
\text { week }\end{array}$ & $\begin{array}{l}\text { Once per } \\
\text { week }\end{array}$ & $\begin{array}{l}\text { Once per } \\
2 \text { weeks }\end{array}$ & $\begin{array}{l}\text { Once per } \\
4 \text { weeks }\end{array}$ \\
\hline $\begin{array}{l}\text { PLPR Inspection System } \\
\text { for plain line CWR }\end{array}$ & $\begin{array}{c}\text { As detailed in } \\
\text { NR/L3/TRK/1015/Mod02 }\end{array}$ & $\begin{array}{l}\text { Once per } \\
4 \text { weeks }\end{array}$ & $\begin{array}{l}\text { Once per } \\
4 \text { weeks }\end{array}$ & $\begin{array}{l}\text { Once per } \\
4 \text { weeks }\end{array}$ & $\begin{array}{l}\text { Once per } \\
4 \text { weeks }\end{array}$ & $\begin{array}{l}\text { Once per } \\
4 \text { weeks }\end{array}$ & $\begin{array}{l}\text { Once per } \\
4 \text { weeks }\end{array}$ & $\begin{array}{l}\text { Once per } \\
4 \text { weeks }\end{array}$ \\
\hline \multicolumn{9}{|l|}{ Note: } \\
\hline
\end{tabular}


Table 1. Basic visual inspections

Passenger and Freight safety by ensuring that a robust inspection and maintenance plan is in place. TRK/001 standard is baseline for all inspection and maintenance activities. Maintenance on a regular basis performing these activities such as: Weld repair, switch repair, inspection, a repeat alignment faults, drainage works. Thera are in some places the ballast is very old and tired, and it is been at some of the locations more than 40 years. Therefore, maintenance is doing some preventable work and such, where alert limits are received from track recording vehicle such as track deviations, vet spots, rotten wooden sleepers. Summer preparation works usually is starting around January time, it does include work as fish plate oil in rail, torching bolts to required settings on the joints this is to prevent any buckles, trap buckles in the hot weather. Methods of track bed treatments as indicated in Figure 1 track maintenance has evolved into two basic groups.

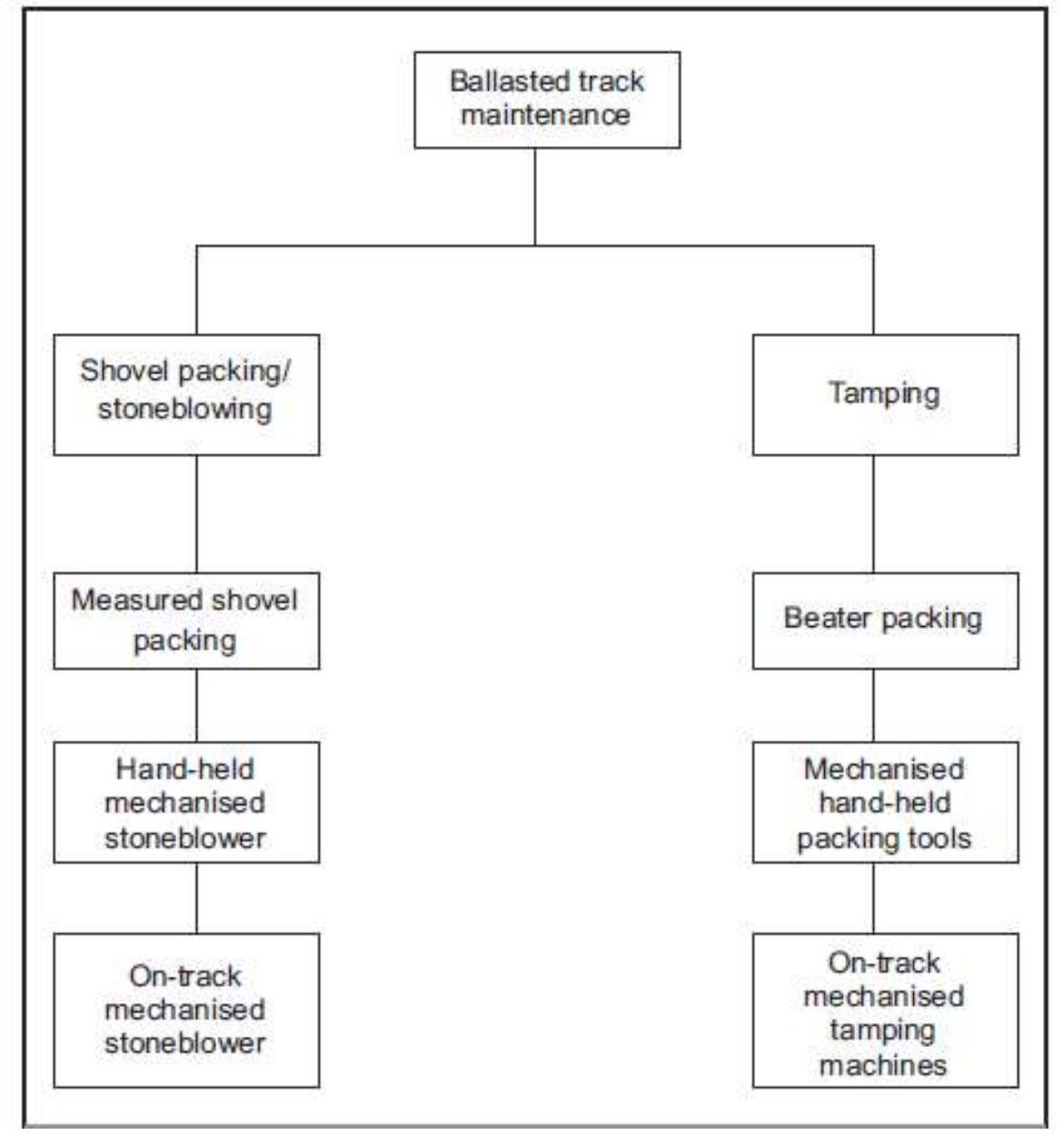

Figure 1. Ballasted track maintenance methods (1)

Ballast tamper

As the continuous stress causes deviations from the ideal track position. If the faults become too large, the track must be tamped.

- Longitudinal level fault. 
- Alignment fault.

- Correcting track geometry faults in longitudinal level and alignment.

- Eliminating voids under the sleeper.

- Constructing defined and stable supports for the sleepers

Consistent consolidation is ensured by applying equal pressure. The machine tines move nonsynchronously, different squeeze path due to the ballast bed. The vibration enables the tamping tines to penetrate more easily. It also facilitates the squeezing process during the consolidation. The fundamental disadvantage of tamping over stone blowing is that each tamping run harms the track ballast by fouling it with smaller particles, and tamped track returns to it pre-tamp position progressively faster after each tamping run. Tamping of the track is said to be the cause of more than half of the fouling of ballasted track in the UK (2). The machine goes along the track, lifting each sleeper and levelling it with compressed air. This produces a more lasting outcome than a tamper, and hence can extend the track's life by many years. According to Coenraad (3), stone blowing stone does not obstruct track drainage; rather, it improves drainage by reducing or eliminating the vertical pumping action of the sleeper. Another advantage of Stone blower is that it produces less damage to ballast when compared to tamping. Figure 2 shows a comparison graph of fines formed by Stone blower and tamper over the course of 10 maintenance cycles.

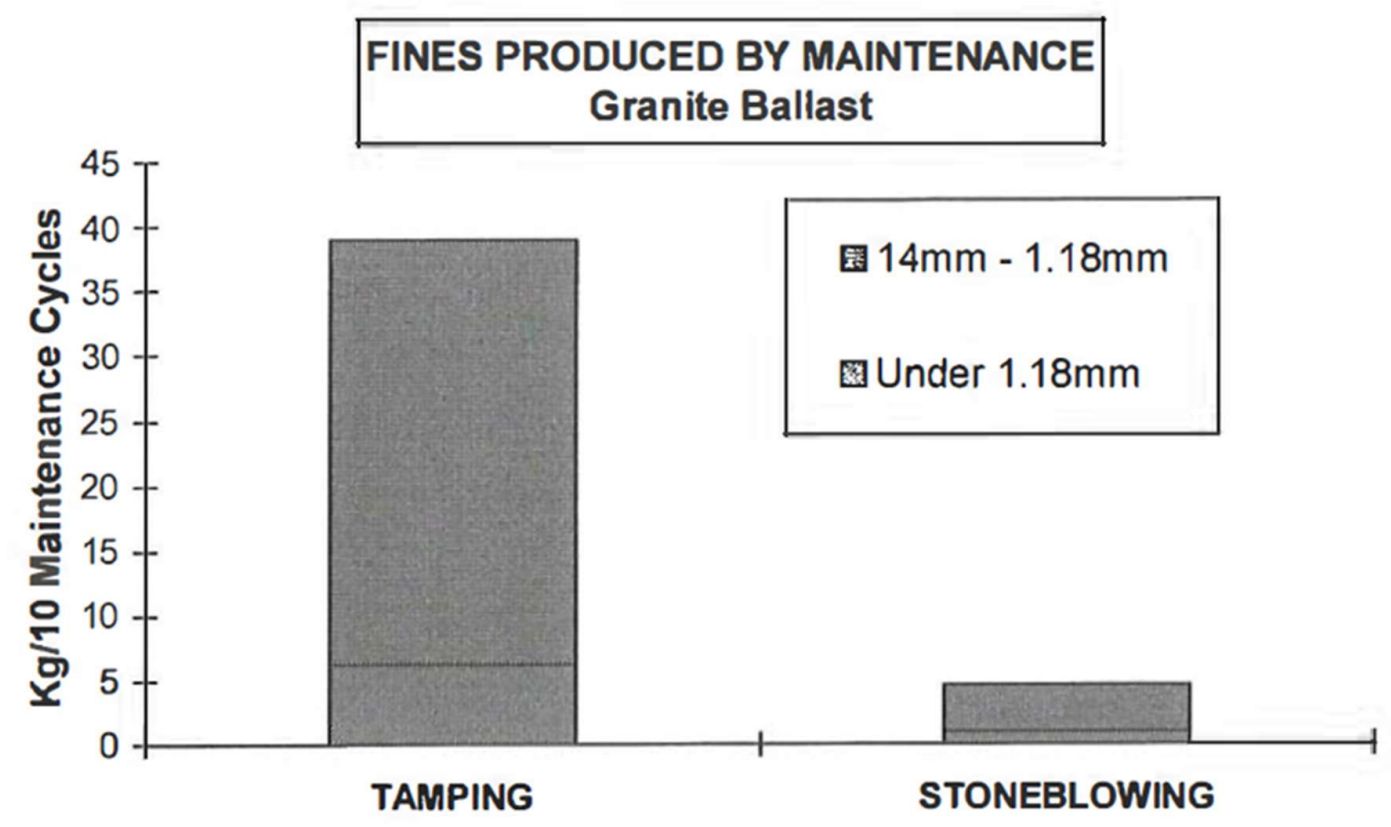

Figure 2 shows a comparison between tamping and stone blowing for fouling (Harsco track technologies 1997)

Ballast cleaning machine

It is replacing the ballast under the rail. It is a rolling hole as far as far as old ballast is removed. The train has 20 wagons full of new ballast and 20 empty ones to take away old 
ballast. New 50mm railway ballast is free flowing of drainage, compact together, allows track to be stiffer.

The handheld stone blower

has been introduced as an effective and efficient way to lift and pack the track using chippings. This method should only be used on poor formations and not with steel sleepers, unlike measured shovel packing, handheld does not require the use of void meters (Figure 1), however they should be used to locate the defect during scoping.

Ultrasonic Test Units (UTU)

In 2006 Network Rail introduced the ultrasonic test units which is using ultrasonic probes- to test rails to identify internal defect within the rail. Ultrasonic probes fitted in within roller search units, so the tires are compressing as they press against the rail roll along the surface of the rail and fire ultrasonic waves into the rail at different angles looking for different types of defects. These units have been very successful in terms of improving rail management regime, as Network Rail records are showing that using only 2-man team, 240 shifts, 19000 miles per annum has been inspected. Where recordings have been taken only at the nighttime at $30 \mathrm{mph}$ at every 8 weeks frequency. The system detects different types defects such as:

- Head defects

- Rail Foot

- Weld - covering all breaks at welds including alumino- thermic, flash butt and weld repairs.

- Rail Ends/ Joints- covering breaks from bolt holes within fishplates joints and breaks along the upper or lower fillet radii at rail ends.

Some of these defects is not even possible detect without these units and if it is left unchecked could lead to catastrophic results.

From the graph below can see a big reduction of breaks per year. These units have improved rail inspection by $90 \%$, even railway infrastructure has gone up more than $50 \%$, where another challenge is that actual access and intervene time to the railway to actually perform maintenance is reduced as well. 


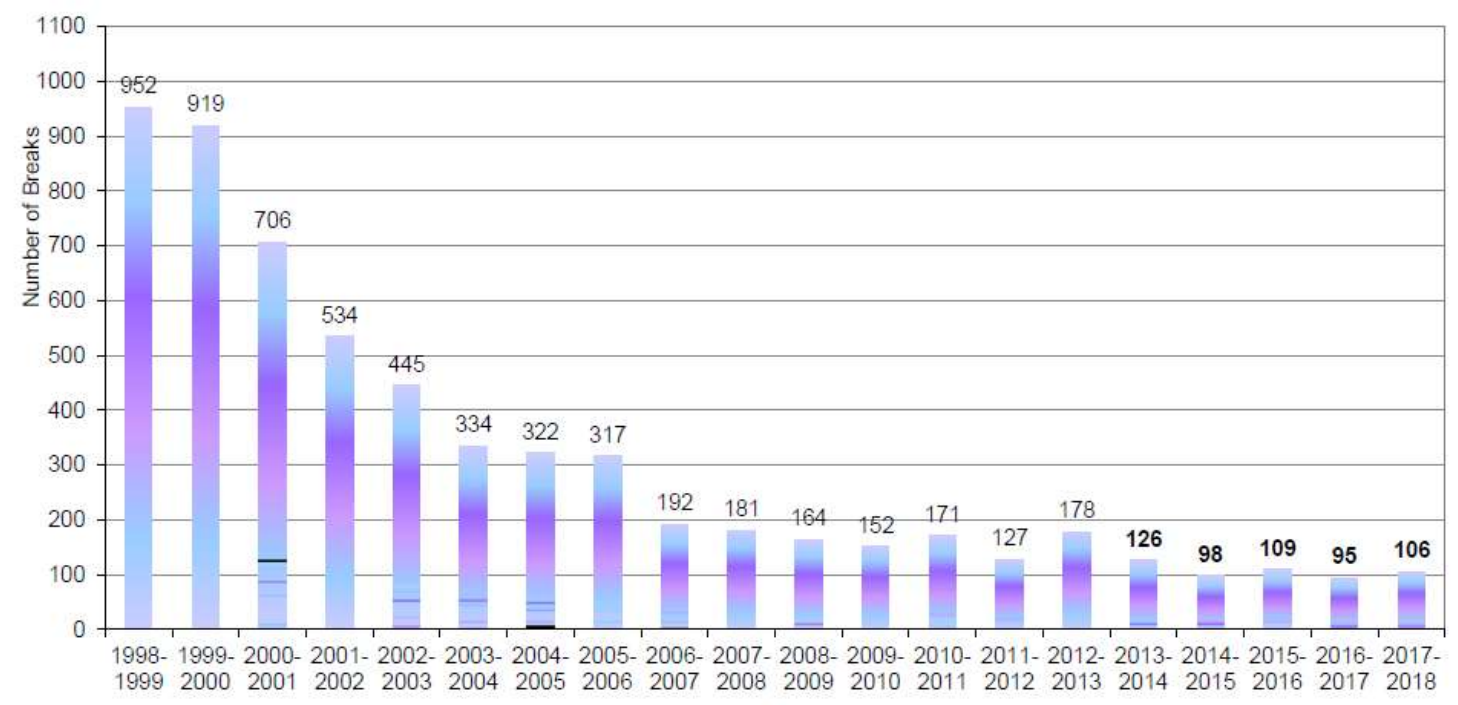

The pie chart shows 29\% Weld defects, 16\% Rail Ends and 39\% Rail Foot, where 5- 6 years later there is a reduction of $50 \%$ of Weld defects, $50 \%$ reduction of rail ends. Therefore, rail foot defects making up a much greater percentage of the total number of breaks. So, challenge is now to try reducing rail brakes even further and there are initiatives in place looking at trying to get numbers down to 50 brakes per year by 2030 and even 30 brakes per year by 2050 .

\section{Rail profile}

The UTU also measuring the rails, there's also rail profile equipment fitted, so that side ware and headwear could be measured. There is Ground Penetrating Radar helping to understand track bed conditions, that could identify wet spots at early stage and determine where renewals are required. From the picture $\mathrm{x}$ the layers in the track bed that it is possible to see between old ballast on the left-hand side and a new ballast starting, where we can see clear interface between clean ballast above and the formation. 


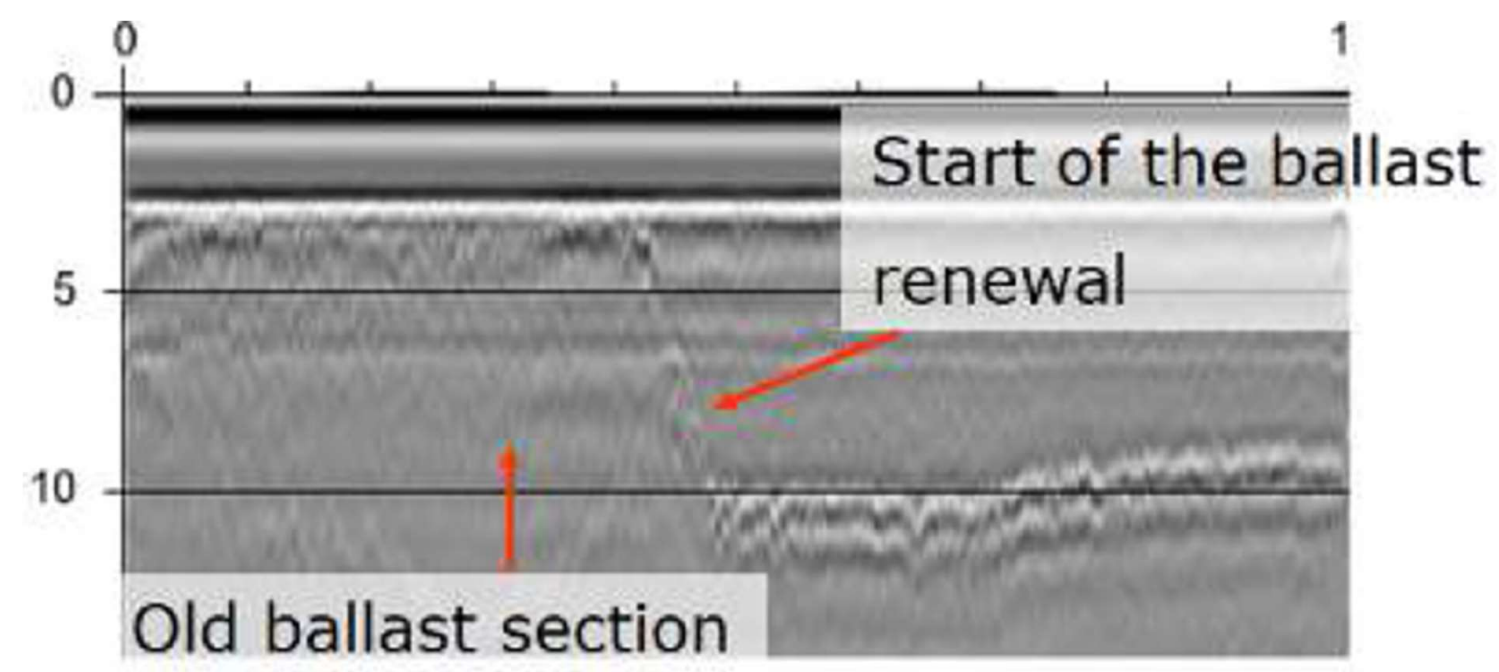

On 2009 UTU was upgraded with the higher resolution antenna. That helped to identify a detailed look at the ballast condition itself and the fouling levels within the ballast. From those records particular and the most suitable treatment was selected, whether is tamping, ballast cleaning or even whole track renewal is required.

These colour coded charts showing where is a blue particularly fouled pieces of dirty ballast and green is a clean ballast. This detailed investigation is providing engineers about the condition of the track bed and what treatments are best for those issues.

Tamping

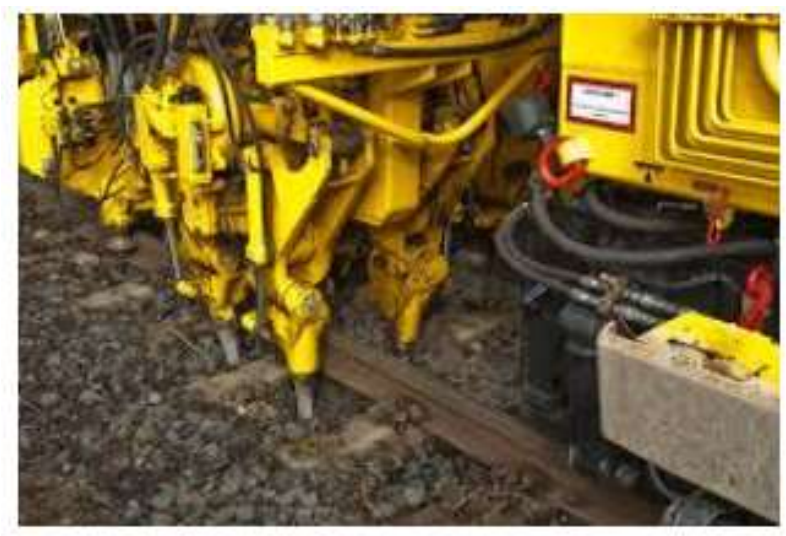

2.6 Geology impact to the track bed

The cyclic shrinkage and swelling associated with periodic variations in weather and vegetation is another key contributor to poor ride quality in certain areas, notably embankments constructed of plastic clay. When a local tracked stiffness problem occurs, it must be repaired and any leftover trigger removed. On I for example, dipped weld remediation would not be sufficient. 
Soil might seem to simply sit still and not do much, but some soils are inconveniently active. Clay soils in particular can soak up water like a sponge. Shrink-swell, or expansive, soils are one of the costliest and globally widespread geological hazards, with costs estimated to run into several billion pounds annually. These soils present significant geotechnical and structural challenges to anyone wishing to build on or in them.

Hallett et al. (1994) (14) identify the following soil materials and effects that are the main cause of ground movement within the UK:

- Clay - Shrink/Swell

- Sand-Erosion

- Peat - Shrinkage

- Silt- Frost heave

- Alluvial soils- Compressibility

- Sulphate Bearings - Ground heave

Brook and Marker (2008) (15) stress that knowledge of ground instability (subsidence) appears to be deteriorating in the planning process, inevitably leading to the possibility of structures not being designed to withstand ground movement, especially with regards to a changing climate.

Groundwater impacts on subsidence

Groundwater has a significant effect on clay minerals, due to their high specific surface areas and the polar nature of water molecules (Gillott, 1986) (16). Whereas with granular soils the removal of the finer material (clay/silt) can result in reorganization of the soil particles inducing settlement, especially when under load or being loaded.

Shrink - swell soils expand and contracts during wetting and drying processes, respectively. This process is causing a huge change of the soil. The highly permeable ballast layer exacerbates soil volume changes due to moisture variation, which leads to unacceptable uneven settlement. The mechanism behind the observed railroads problems on expansive soils, and the associated (possible) remedial solutions, are still unclear (12). Existing railroads in the UK are facing challenging problems, such as mud pumping, wet spots

Soil moisture deficit

During continued periods of dry weather, the Soil moisture Deficits (amount of water needed to saturate the soil) increases. This is caused by thirsty trees sucking water out of embankments made of clay, and this makes them settle (desiccation). This causes track quality to deteriorate leading to temporary speed restrictions. Track geometry declines due to clay soil shrinkage. Rough rides occur when ballast/ ash collapse into voids left at ash clay interface. Ground shrinks due to water being removed from it. NR/L2/CIV/086 Module 13, page 36 provides details of the trees that cause most track settlement. These are termed very high-water demand trees - such as English Oak, Poplar, Ash and Willow. Selective removal 
of these trees can reduce the impact of dry weather on over consolidated clay embankments. The process used is typically to determine a list of embankments at risk and overlay local knowledge and history of track settlement. These locations are then visited, and the following trees selected for removal:

- Very high water or high-water demand;

- > 500mm diameter;

- Growing in the top $1 / 3$ of the slope (height of slope being from ground level to crest).

Trees at the toe of clay embankments improve stability and should not be removed. They also act as a screen between homes and the railway and increase biodiversity. Scientific interest in swell - shrink processes in soil was establish by Tempany 1917 and Haines 1923. Clay related subsidence affecting predominantly the top two metres of ground, that which is most influenced by changes in soil moisture (Harrison et al. 2012) (17), however Hawkins 2013 has shown that this could extend to depths of $2.5 \mathrm{~m}$.

The south east of England is particularly prone to swell - shrink processes, this is due to the geological clay formations that are presenting including (Samuels, 1967) (18). The London Clay formation arguably poses the greatest risk to foundations within the UK (Crilly, 2001) (19). 


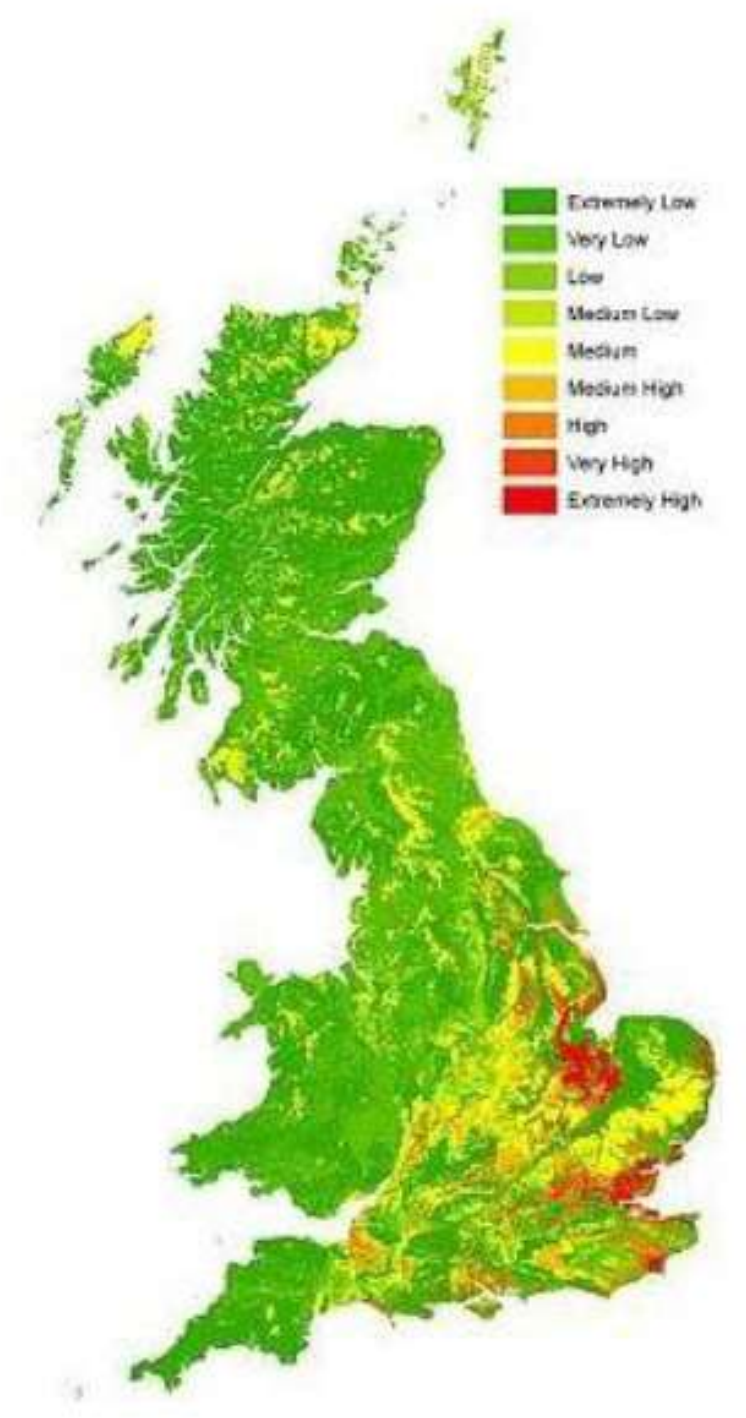

Figure 10: The susceptibility of UK soils to clay related subsidence (NSRI, Cranfield University)

Soft soils and high velocity trains (page 46)

Ground vibration caused by the passing of surface trains has recently gathered interest (Sheng et al. 2003) (19), with it likely that trains may exceed the propagation velocities of waves in soft soils. Timoshenko (1927) first hypothesis that a rail and sleeper system 'elastically' supported on ballast should have a critical speed as to which excessive dynamic amplification of vertical motion could be expected. Yang et al. (2009) showed that dynamic effects of Rayleigh waves became apparent when train speeds were greater than $10 \%$ of the Rayleigh wave speed of the subgrade material (soils), at $50 \%$ the shear stresses acting upon the subgrade will be underestimated by $30 \%$ in static analysis and with train speeds greater that the wave velocity the dynamic effects increase dramatically. 
Train acceleration and braking amplify the effects of increased shear stresses and horizontal displacements in the soil.

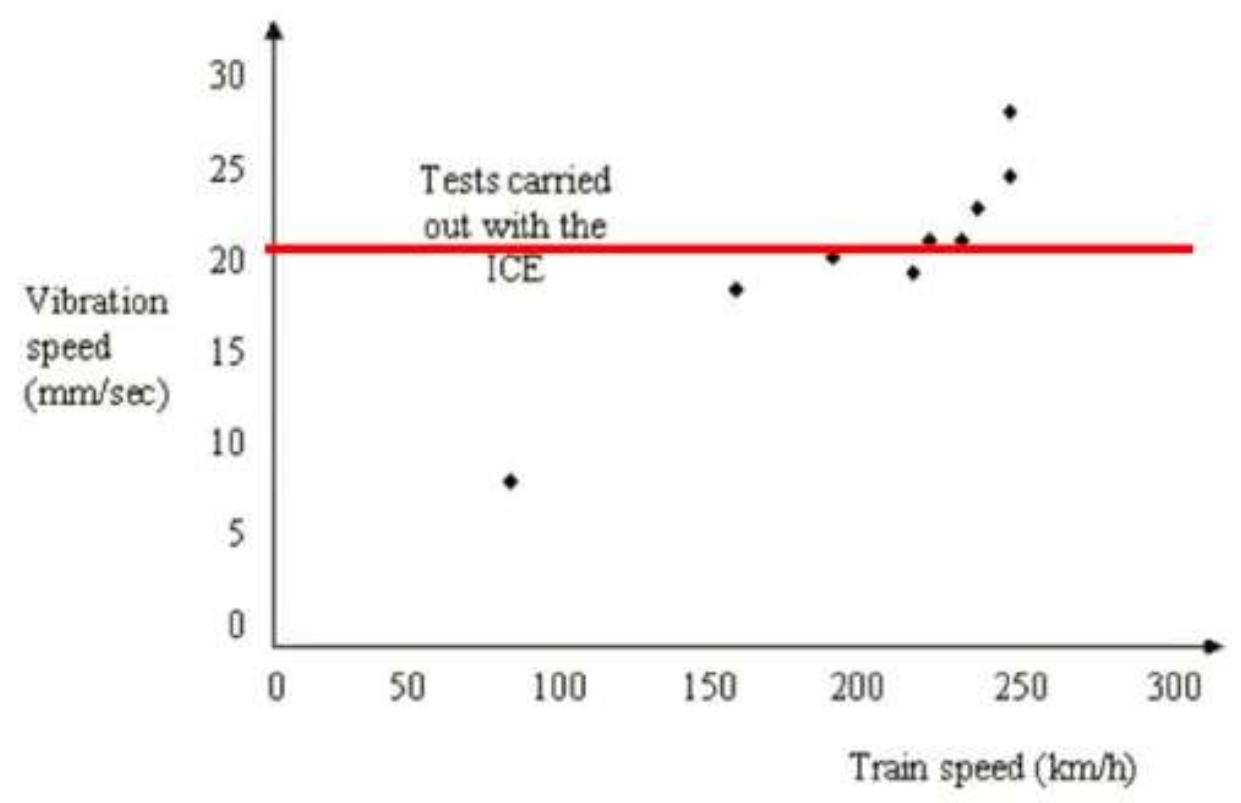

Figure 1. Unmodified ballast PPV with train speed as reported by Pita et al., 2004

Figure 1 is a plot of the vibration speed in the ballast peak particle velocity (PPV) versus the train speed where is showing that with increasing train speed PPV is increasing too. This is natural movements as the train getting faster the sleepers going down and pushing ballast down as it goes through. The major changes are happening when it is passing $20 \mathrm{~mm} / \mathrm{s}$ as a vibration speed. The work after Banimahd and Woodward (2012) was published, which shows plotted the critical ratio against particle velocity for a subgrade of about $25 \mathrm{MPa}$. Results are showing that once a critical ratio about 6 is reached, the peak particle velocity started to exceed $20 \mathrm{~mm} / \mathrm{s}$. As the critical curves were plotted in terms of the dynamic deflection divided by the static deflection, findings are showing that dynamic effects occurring once critical speed ratio was passing point 6. High axle freight loads are problematic on soft soil sites, because they cause excessive track deflection. Similarly, faster trains are problematic because when the train exceeds approximately 50\% of the natural ground wave speed, increases in track deflection occur (Dong, 2018). If deflections are high, it is a safety concern and results in more frequent maintenance due to acceleration track degradation. As I have found out, that cement columns were used to stiffen the soil in Lessard (Sweden). The columns were taken down to a depth of $13 \mathrm{~m}$ (max) below the railhead to stop Rayleigh wave formation.

It is also shown that track height plays an important role with increases in slab track thickness and reductions in ballasted track thickness both causing increases in critical velocity. Furthermore, it is found that soil saturation affects critical speed considerably (by up to $12-$ $17 \%$ depending on track type) because changes to Poisson's ratio alter the dispersion 
characteristics of layered soils in the mid-frequency range, where critical velocity effects occur. Finally, it is shown that rail pad stiffness has a low influence, and that increasing the rail bending stiffness on ballasted tracks increases critical speed.

\section{Track Bed Remediation (not finished)}

Wet spots repair

Slurry spots look like cement paste covering the sleepers and ballast and is mainly formed from concrete powder and water. The powder is generally produced by a grinding action between the base of the concrete sleeper and the ballast, but it can be added to by spillages from passing trains such as coal dust. Tamping machines and demolition hammers can also aggregate this problem by crushing the ballast and sleepers when consolidating the track. The slurry forms a barrier preventing drainage which will accelerate the size of the slurry spot

Geometry repair (NR/L2/TRK/001)

Measurement of track geometry shall be undertaken on all passenger running lines, good running lines, carriage lines and loops, including all crossovers and turnouts. The routine inspection as it shown in Table 3 and maintenance regime will be sufficiently detailed to allow the identification and rectification of geometry faults before they present an unacceptable level of risk, these inspections include manual measurement of track geometry, cab riding and detailed examination.

Remediation:

Micro piles, manual hand packing could be in some cases very effective, unfortunately where track is suffering from the greatest deterioration in track geometry these remediations are not effective. Replacements of the track, with the ballast and sub- base dug out to a depth of $500 \mathrm{~mm}$ below sleeper base level the placement of a honeycomb geosynthetic (Geoweb) layer $200 \mathrm{~mm}$ deep filled with stone chippings, underlain by an impermeable geocomposite.

Many researchers agree on the theory, that the fundamental quality of a track is mostly determined by the track's stiffness characteristics, whether it is too stiff, too soft or too variable. Also, it is discussed the relationship between track quality, stiffness variation, and ballast conditions and how this relationship can be utilised to evaluate alternative remedial 
solutions. A further major contributor to many of the track bed problems is the cyclic shrinkage and swelling associated with a seasonal change in weather and vegetation.

As a result, the primary purpose of tis dissertation is to research at new and existing methods for treating track bed issues, as well as the causes of these problems.

How can we ensure that current UK railway maintenance projects are future-ready, preventing infrastructure concerns and the need for huge investments to be repeated in the future?

The biggest concern is that even if the track bed is completely rebuilt and maintained according to the resent standards, the tack condition does not always improve.

\subsection{Geotextile}

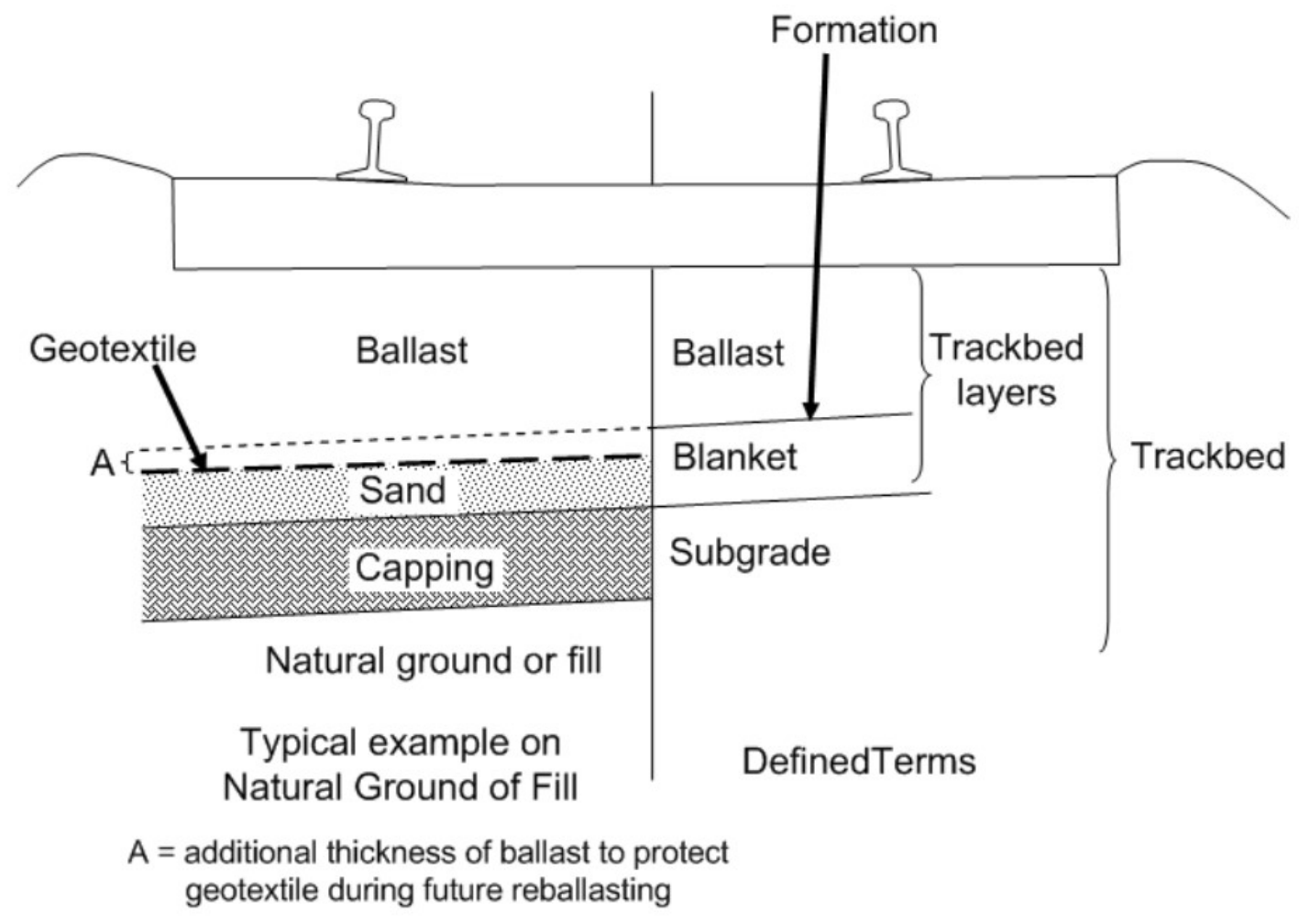

Keeping on track with Geosynthetics

Lower maintenance, cost, carbon and building with more resilient, for issues such as climate change. Extending life of track and building more resilience. The geosynthetic materials is helping to increase the design life of natural materials such as the soil, the rock and make them work more efficiently.

ISO 10318 Definition: Geosynthetic - it is a generally flat material, where most geosynthetics are rolled materials. At least one of whose components is made from a synthetic or natural 
polymer, in the form of a sheet, a strip or a three - dimensional structure. Used in contact with a soil and/ or other materials in geotechnical and civil engineering applications.

On the picture 1 is shown the ISO definition of what a geosynthetic does.

It is very important to identify issue first, before product is chosen, to achieve the most efficient results.

About $60 \%-70 \%$ of all geosynthetics are made and used for separation geotextile, where geotextile is permeable geosynthetic material, which allows water to pass through the ballast and ensure a stability of it. It helps substantially in a rail application by keeping ballast clean of fouling and away from rails such as unsurfaced roads. The use of a separation geotextile can extent their design life by ensuring that separation is maintained between the compacted granular materials and soft grounds.

\begin{tabular}{|c|c|}
\hline Geosynthetic Types & Criteria for Use \\
\hline $\begin{array}{l}\text { Normal Separator (can be woven, } \\
\text { non - woven, needle punched, heat } \\
\text { bonded) }\end{array}$ & $\begin{array}{l}\text { Protect existing or new blanket and prevent migration } \\
\text { of fines into ballast. }\end{array}$ \\
\hline $\begin{array}{l}\text { Robust Separator (consists of two } \\
\text { layers of geotextiles separated by } \\
\text { mesh grid or a very strong single } \\
\text { layer material) }\end{array}$ & $\begin{array}{l}\text { Coarse granular materials where is a risk of abrasion } \\
\text { and minor sub - grade erosion. }\end{array}$ \\
\hline $\begin{array}{l}\text { Grid Reinforcement (large aperture, } \\
\text { bi- axial or tri - axial) }\end{array}$ & $\begin{array}{l}\text { - All conditions where settlement/ differential } \\
\text { settlement is a problem; } \\
\text { - Where soft ground conditions are present; } \\
\text { Through level crossings (no shallow } \\
\text { bedrock); } \\
\text { - Transitions between structures and abutting } \\
\text { plain line, with variable track stiffness. }\end{array}$ \\
\hline 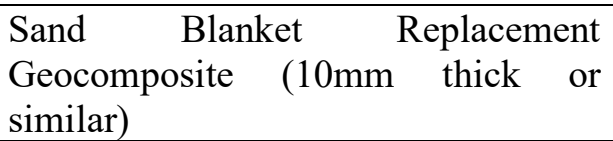 & $\begin{array}{l}\text { Where subgrade erosion is present, or material are } \\
\text { susceptible to erosion }\end{array}$ \\
\hline Geocells & $\begin{array}{l}\text { - Where extremely soft underlying conditions } \\
\text { are present; } \\
\text { - Transitions to very stiff structures where the } \\
\text { track stiffness needs to be regulated. }\end{array}$ \\
\hline
\end{tabular}

The geocomposite drain is slowly and continuously deformed under long lasting shear and pressure forces. The thickness is reduced and thereby the drainage capacity. If the in-plane deformation reaches a critical value in the course of time, shear failure might occur. Likewise, if the thickness reaches a critical value the structure of the drain core might collapse. These effects were demonstrated using data provided by geocomposite drain manufacturers. These special properties of the long-term performance of geocomposite drains must be considered when designing long-lasting geotechnical constructions. There are both positive and negative environmental side effects associated with the usage of geosynthetics in 
geo-environmental engineering. The items are small and light, making them simple to handle and move. As a result, using geosynthetics throughout the construction process might significantly cut greenhouse gas emissions (measured in carbon dioxide equivalents). Environmental concerns refer to the accumulation of plastic debris in the environment after the end of life of the constructions and to the emission of ecotoxic additives in the plastic material into the environment. Both problems can be solved by an appropriate choice of the basic polymeric materials used for the geosynthetic products. When geosynthetic reinforcement was employed, the performance of ballasted track was examined. This study indicates that various types of geosynthetic layers increase performance on fresh ballast while also emphasizing its potential application with recycled ballast. When reinforced with appropriate types of geosynthetics such as woven - geotextiles, geogrids, and geocomposite, recycled ballast performs effectively under repeated train loads. When geosynthetics were installed, settlement in both new and recycled ballast was greatly decreased (Indraratna B. et al., 2009).

\section{Rail deflections}

Rail deflection increase due to axle load, thickens of the embankment fill, elastic properties of the sub- soil and the damping in the system, train speed. Where increase in train speed is increasing in vibrations generated. These vibrations take the form of: Compression waves; shear waves and Raleigh waves which result in surface and near surface deformation. High train speed can result in critical velocity problems, at which point track deformation may be excessive leading to possible derailment.

https://www.thepwi.org/technical_hub/presentations_for_tech_hub/171019 high_speed_rail_ lines_tech_challenges/04_171019 high_speed_rail_lines_tech_challenges_ghataora

\subsection{Micro piling}

\subsection{The polyurethane}

To apply the polyurethane to the ballast structure to stabilize it was developed at Herriot Watt University, where it was tested and completed formal trials. And it could be proofed very clearly that the polymer significantly increased the strength and resiliency. How to improve maintenance, reduce the amount of access needed for maintenance and to keep maintenance cost down. So, in terms of approval is fundamentally a good way forward, it is quite sophisticated and enables both the compression and tensile forces in the track to be managed in the way that it is never been able to do before. High speed railway is one of those areas which is of most interest not only to academia and the industry, but also to the public. So, the software we are developing DART3D is Dynamic Analysis of Railway Track 3D. It is numerical program that is capable of modelling the whole train track interaction system. The 
challenge in the railway industry is being able to prove these technologies. So, that would lead to the system like a GRAFT (Geo-pavement and Railways Accelerated Fatigue Testing). The GRAFT facility is the largest test unit in the UK and one of the largest in the Europe.

The polymers used are urethane cross linked polymers that are applied directly to the ballast matrix using on site mixing equipment. Application of the urethane cross linked polymers allows a high degree of viscoelasticity and hence polymer damping characteristics. The formed structure cures within seconds to form a resilient and very strong polymer/ballast geocomposite. Desired frack fault remedy attributes:

3D polyurethane reinforcement

It is considered that any proposed reinforcement technique must satisfy the following criteria in order to provide cost - effective solutions:

1. The treatment must provide $3 \mathrm{D}$ elemental type reinforcement across the track.

2. Increases in ballast stiffness and strength should be designable to suit operational and track requirements.

3. The material must exhibit ductile properties and hence tend to absorb energy to prevent brittle types of failure.

4. The treated ballast should remain free draining.

5. The work must be relatively quick and return the track to operational use by the end of the possession.

6. Breakdown of the treatment should revert the track back to a normal ballast state.

7. The treatment must satisfy environmental regulations.

8. The treatment should primarily be considered for long - term solutions to significantly reduce future track maintenance.

The polymer is applied in - situ by mixing two components through a delivery hose, which contains mixing elements.

Typically, the polymer cures within $10 \mathrm{~s}$, forms $50 \%$ of its strength within minutes and reaches $90 \%$ of its strength within $1 \mathrm{~h}$. The polymer satisfies the requirements of the UK Environmental Agency and can typically develop strains in excess of $100 \%$ before failure in tension.

Figure 6. Application of the polymer XiTRACK to the ballast surface

The ductility and damping properties of the polymer reinforcing elements make it an ideal material for railway environments where operating conditions can result in suddenly high dynamic loads (e.g., insulated bolted joints, wheel flats. Breakdown of the polymer leads to conventional ballast and drainage still maintained. Provided the ballast voids are relatively clear the treatment can take place with the minimum of $\mathrm{p}$ - way work. It is normal however that the ballast excavated down to the sleeper bottom level to allow conventional maintenance to occur should the need arise. 
In this case a high-performance polymer was presented for the reinforcement and stabilization of railway track at all train speeds and axle weights. The use of 3 - dimensional finite element techniques was presented in order to demonstrate how the polymer can be used to solve track related issues. The paper concluded by presenting a Case Study of the polymer application at a site near Bletchley Station in the UK on the West Coast Main Line. Feedback from the network operator confirms that no maintenance at that location has been required since reinforcement, now representing over 9 years maintenance free operation, where previously it required maintenance every 3 months (Woodward et al., 2009). The paper has therefore clearly shown the potential of the technique to reinforced railway track and prevent the formation of track faults.

\section{No 1. Case Study}

Site overview

The Warf level crossing near Purfleet, Essex is part of the Tilbury Loop Line, which serves both local passenger and heavy freight trains. The private, heavily travelled road includes the accommodation level crossing. Because of the expected growth in rail freight and the container port's use of the level crossing, which is expected to increase from one container lorry every $30 \mathrm{~s}$ to one every $15 \mathrm{~s}$ in the near future, a more resilient solution for the site was required.

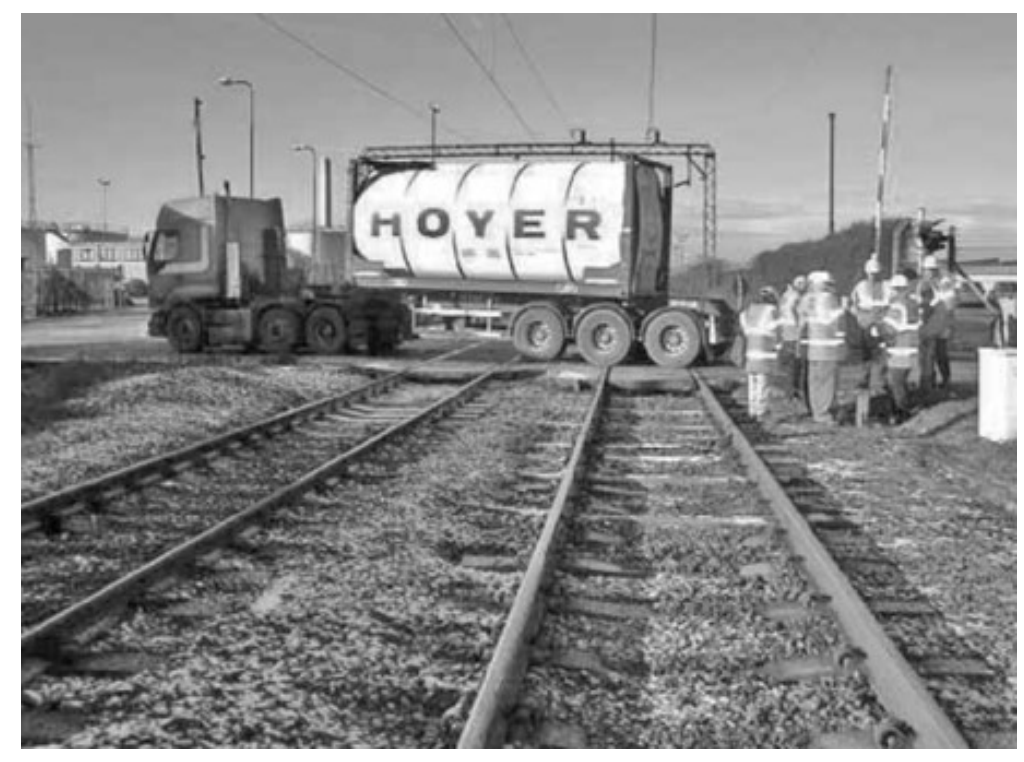

Figure $\mathrm{x}$ Typical road vehicle loading

Case problem

Because of the poor nature of the formation, which consisted mostly of very weak formed ground above very weak alluvial soils and silts, the level crossing displayed evidence of both bearing failure (cess heave) and severe plastic deformation (pocketing and rutting) (Woodward, 2007). Alluvium clays known to exist in the sub grade. In view of the current 
and anticipated future loading conditions, along with needing to minimise line closure time, a XiTRACK treatment was considered desirable in order to provide a long-term cost-effective solution.

A XiTRACK design was prepared for the site and polymer applied in the specified loading pattern and, including all groundworks.

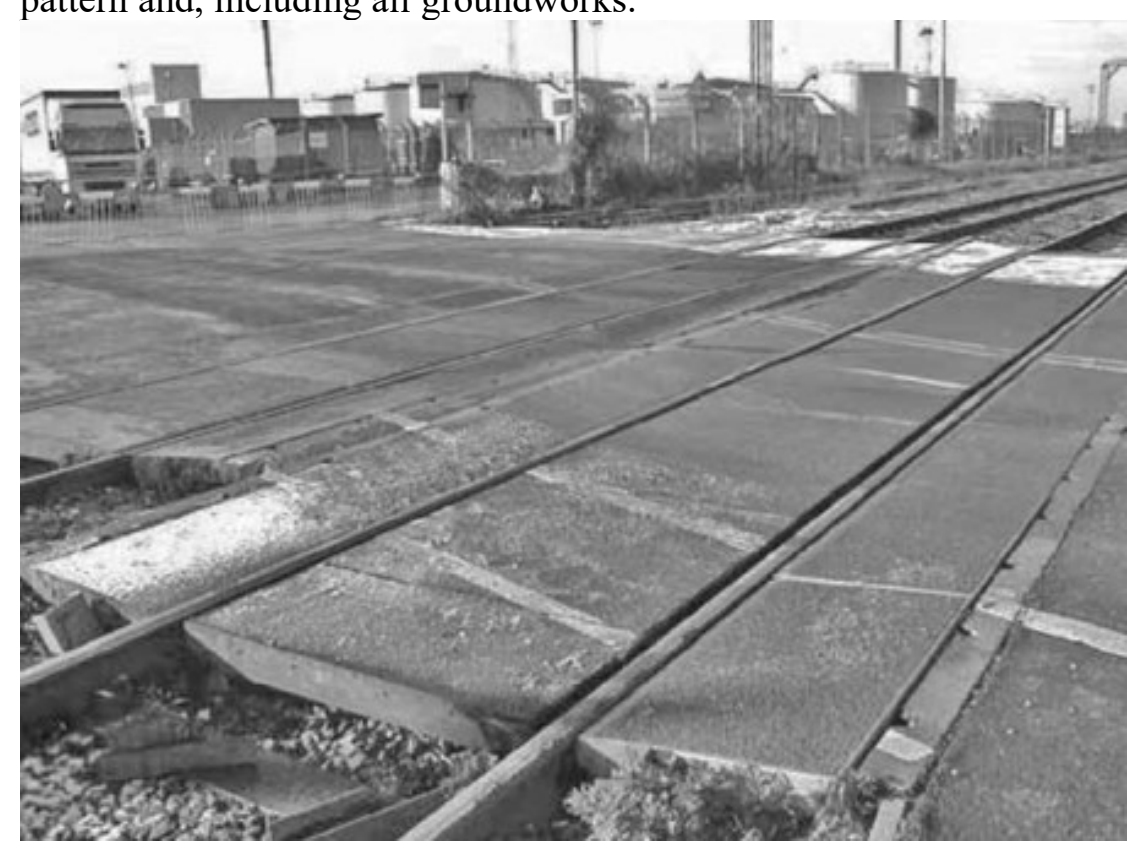

Figure x Purfleet Deep Warf level crossing before renewal

The sequence of events

The level crossing, track panels, rails, and sleepers were removed first. Following that, ballast and soil were excavated to the design depth, and the transition slopes on either side of the level crossing were created. After that a sand blanket was built over the subgrade to prevent contamination of the ballast and geocomposite by the alluvial soils beneath. On top of that, a geotextile separator was installed to assist prevent sand from contaminating the ballast. Afterwards, compacted ballast was placed in phases and the design area was treated with the polymer as illustrated above in Figure 11. To lessen dynamic forces, transitions were built to allow a progressive change in track stiffness from the untreated to the treated track. The ballast depth was gradually reduced towards the standard track to help manage the change in track stiffness, and traditional geogrids were also employed in layers to help manage the change in track stiffness. Between the geocomposite and the sleeper bottom, a top layer of untreated ballast was laid to allow for track geometry correction after construction with a tamper, as well as future track maintenance if necessary. The provider designed the geocomposite treatment, as shown in Figures 7 and 8. 

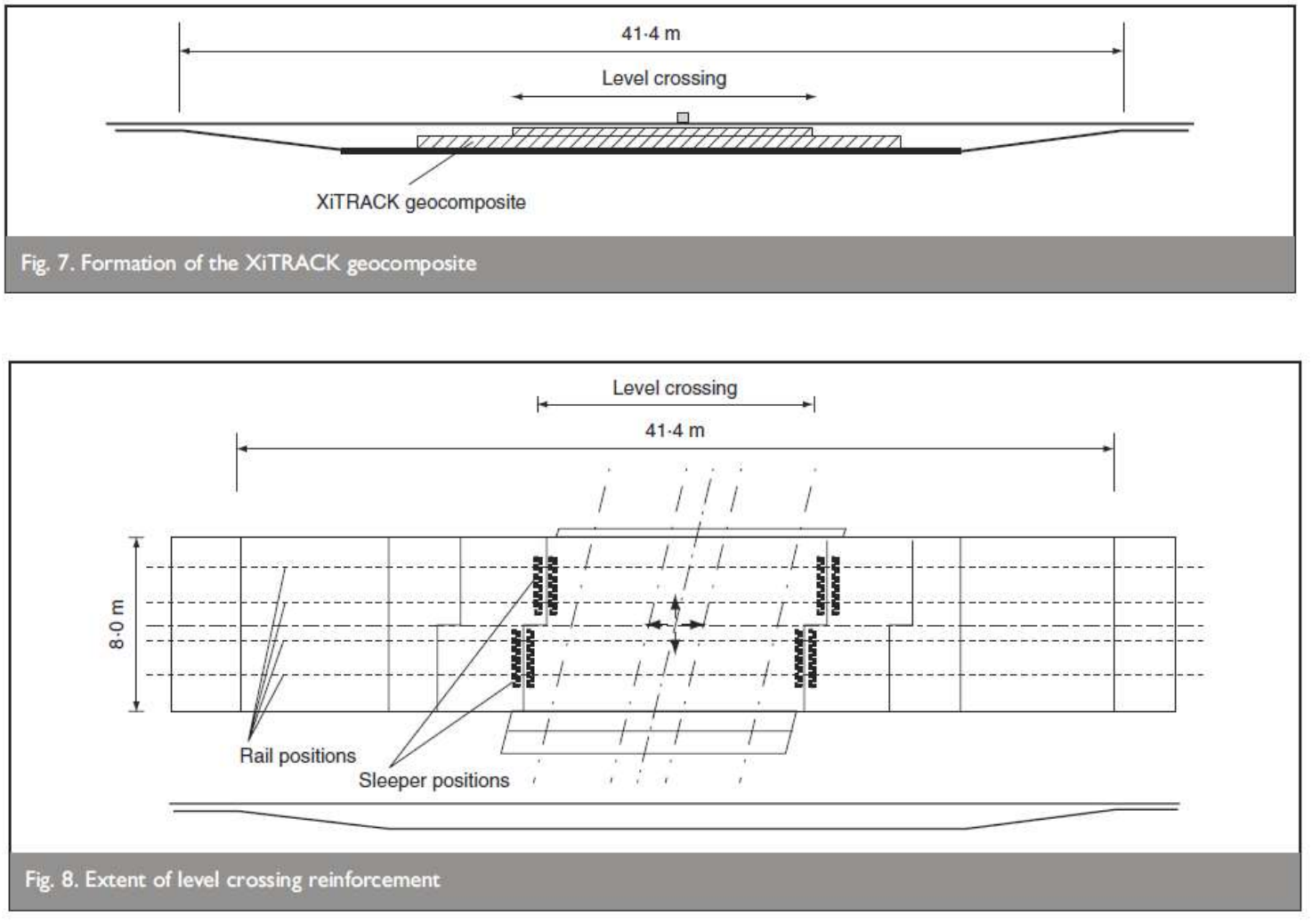

Figure 8 depicts a plan view of the scope of the construction, as well as the level crossing, which includes the road skew.

The polymer installation took only 12 hours from the initial pouring. The reinforced ballast could be driven over 15 minutes after the polymer was poured, and the whole renewal time was only 70 hours, significantly less than previous methods offered for the location. This quick installation resulted in significant construction cost savings as well as the avoidance of any financial penalties associated with track stoppage. 


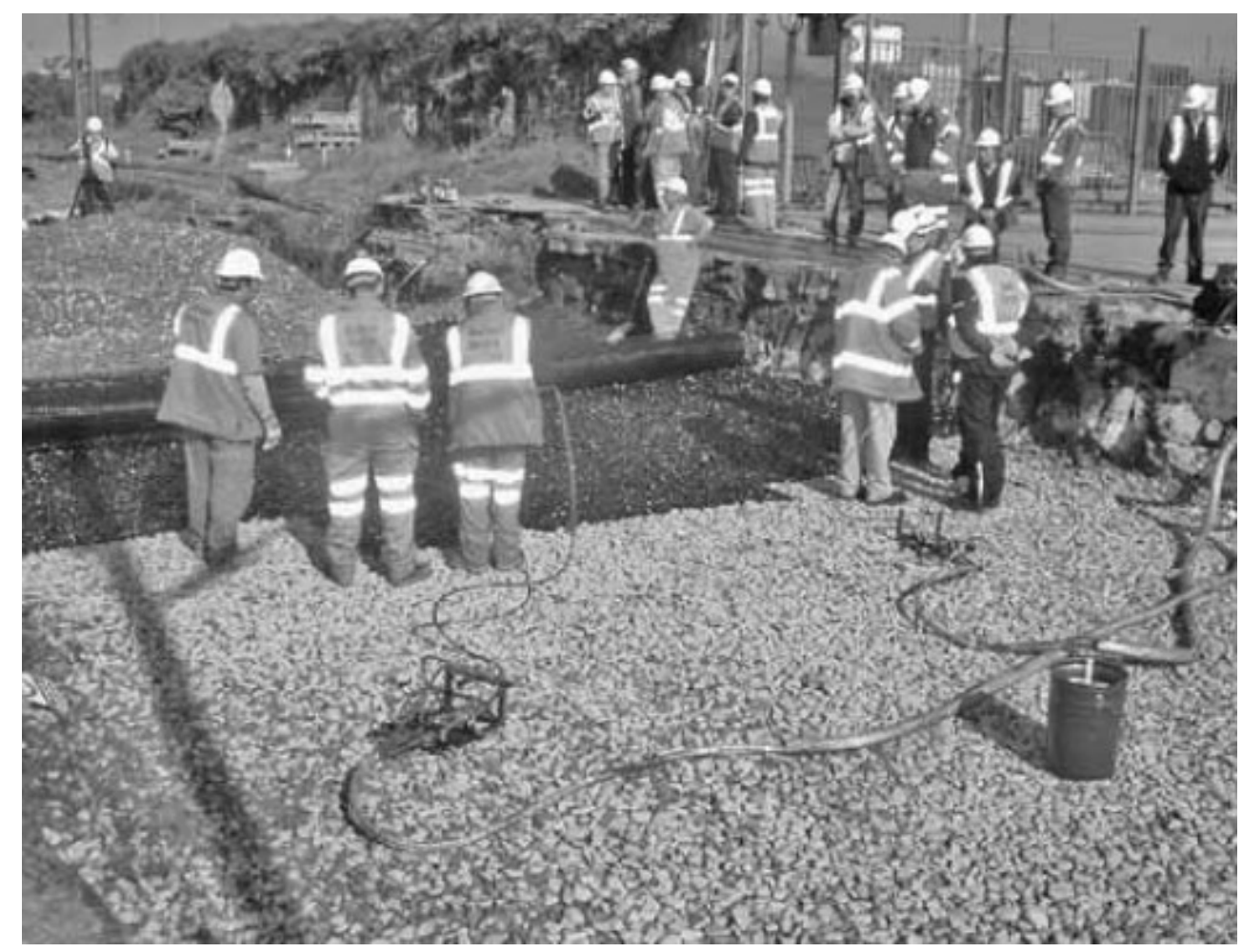

Figure 11. Application of the polymer

\section{Conclusion}

The site was returned to full rail and road traffic after a total closure time of only three days. As a result, the solution is expected to last a long time. The bearing pressure decrease is especially essential because the level crossing's motorized road usage is expected significant increase. By leaving an unreinforced zone right above the reinforced ballast, all traditional track maintenance techniques can be employed to fix any track problems that may arise. Furthermore, the porous structure of the geocomposite allows any created excess pore water pressures to be dissipated through the sand blanket and into the reinforced ballast. The XiTRACK three-dimensional track strengthening system has proven to be extremely effective in solving difficult, long-standing track issues on the railway. As a result of this accomplishment, the approach was standardized for usage in Purfleet. 


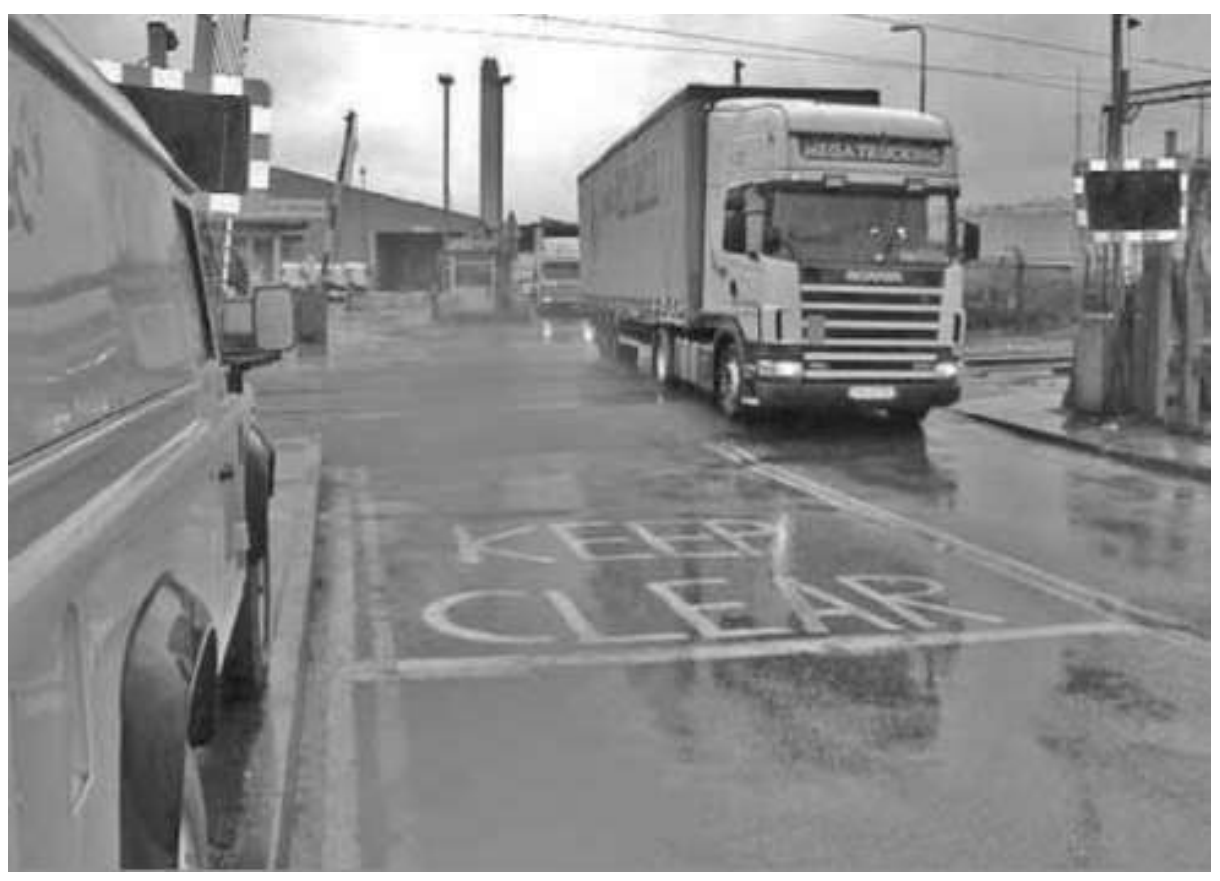

Figure x Completed renewal at Deep Wharf level crossing

No 2. Case Study

Site overview

\section{Gravel Hole (too soft): Subgrade stiffening using micropiles}

Large track displacements began to occur at this site following an increase in line speed from $160 \mathrm{kph}$ to $200 \mathrm{kph}$ in 2006. The track is located in a cutting with a high-water table; and is underlain by a horizon of peat, over layers of stiffer sand, clay and gravel. The peat layer varies from $1.4 \mathrm{~m}$ to $4 \mathrm{~m}$ in thickness, and its low stiffness was considered to be the main cause of the large track movements. Following a recent renewal there was no obvious indication at the track surface (Figure A2.1) of anything untoward.

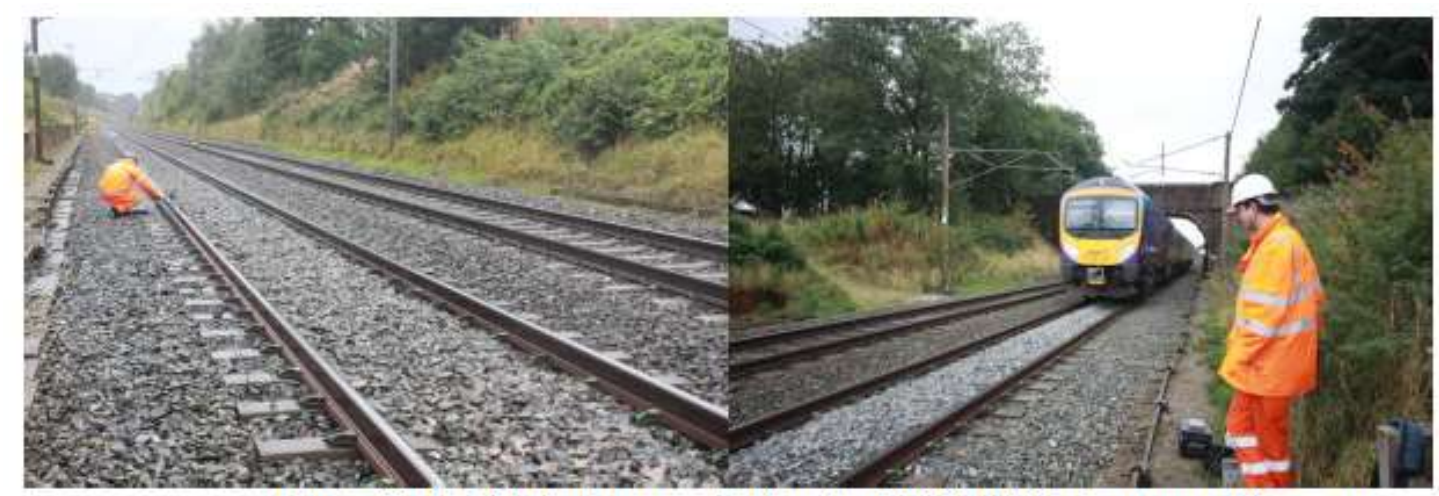

Figure A2.1: (a) Prior to remediation, Sept 2013 (b) Train approaching zone

\section{Remediation}


Micro piles with enlarged caps were placed in the cribs between alternate sleeper pairs to transfer loads down to competent soils below the peat (Figure A2.2). The remediation was carried out in or around January 2014, followed by stone blowing in March 2015.

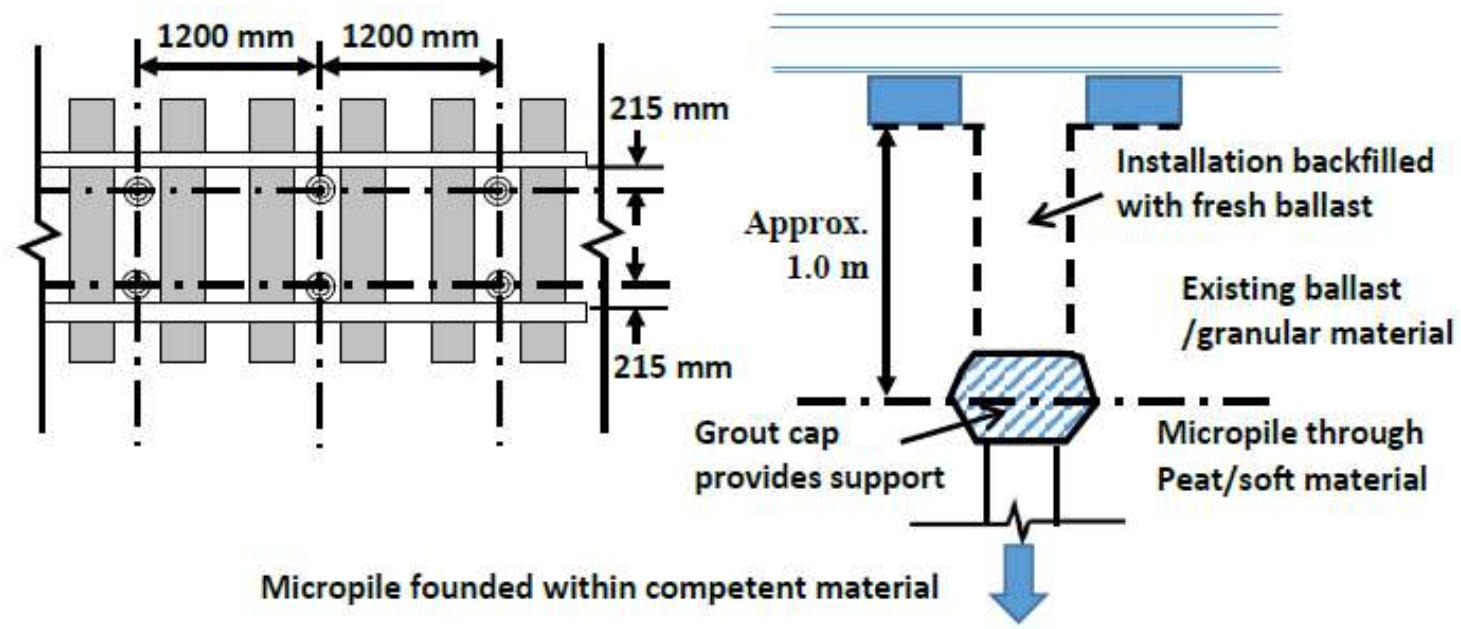

Figure A2.2: Remediation design (not to scale); (a) plan; (b) illustrative elevation of individual pile

Measurements

Nine geophones were mounted on every other cess side sleeper end to quantify track movements before (September 2013) and after (November 2014) remediation. During an interim visit in June 2014, 13 broken rail clips over a length of 26 sleepers through the middle of the site were noted. These were replaced prior to the November 2014 visit, during which only one broken clip was observed. Track geometry data from measurement trains were also available for evaluation.

Results

For simplicity, geophone data from only two trains are compared in Figure A2.3. These were nine car class 390 Pendolinos travelling at 52m/s and 57m/s during the September 2013 and November 2014 visits respectively. Figure 4 shows track geometry data from 2006 to 2016.
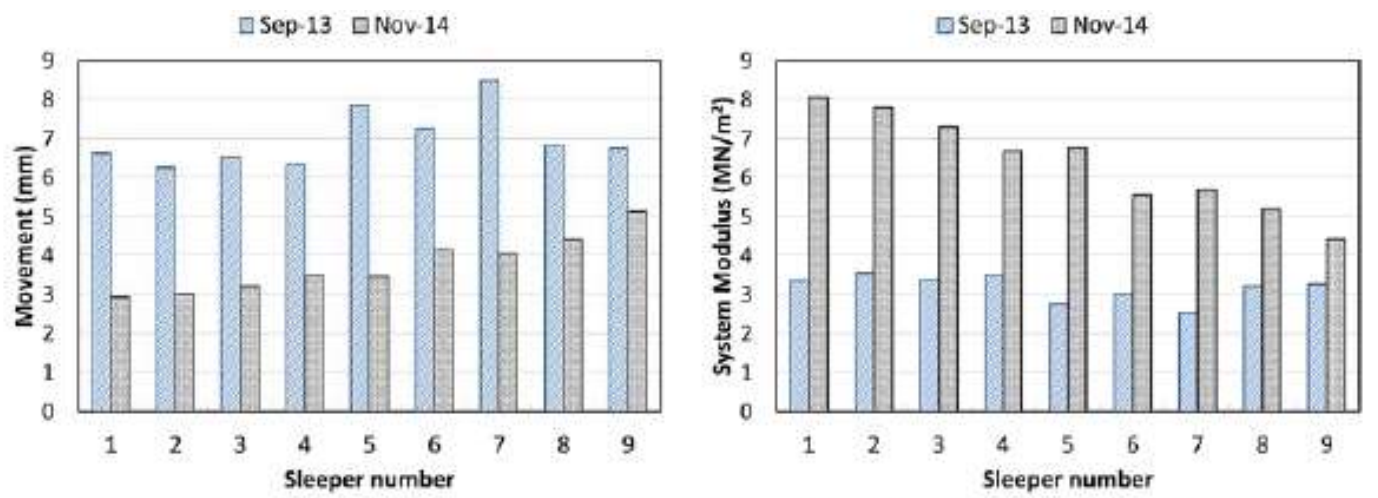

Figure A2.3: (a) Average sleeper vertical deflections (b) Support system modulus 


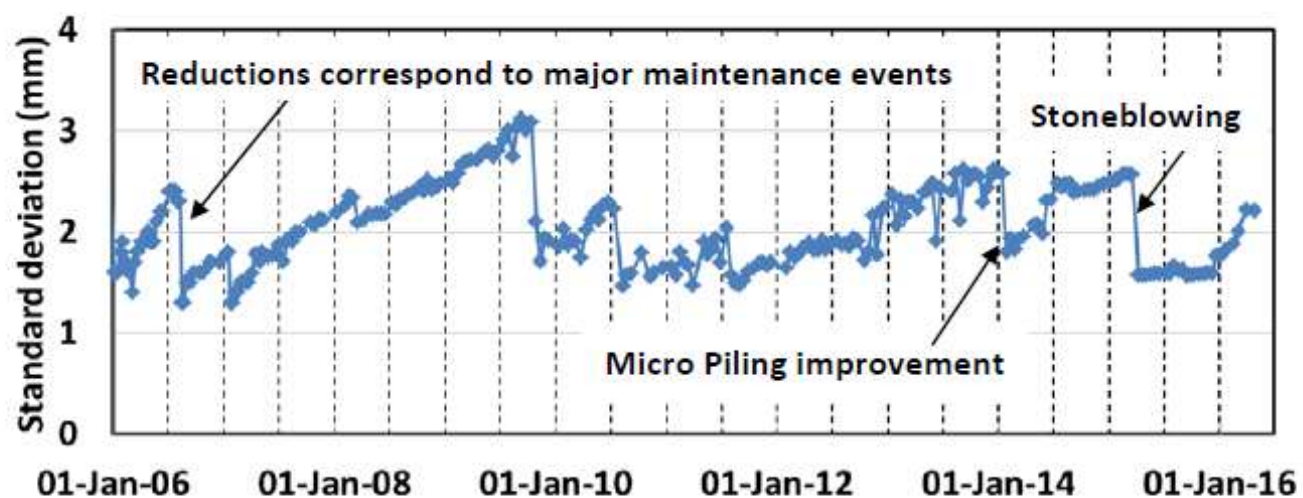

Figure A2.4: Vertical (worst top) standard deviation over a $35 \mathrm{~m}$ wavelength for a 220 yard length of track including the study site

\section{Observations}

The placement of the micro-piles significantly reduced deflection magnitudes (Figure A2.3). However, the site continues to exhibit signs of soft support conditions, for example the broken rail clips observed during the June 2014 visit. The track geometry data showed a step improvement following micro piling (January 2014) and again following stone blowing (March 2015). In any future remediation of this type it may be preferable to place micro piles in all (rather than alternate) cribs.

No 3 Case Study

The site is situated on the Monks Lane, UK. Service trains are class 171 diesel multiple units typically in 2, 4 or 6-car formations travelling at up to the line speed of $113 \mathrm{~km} / \mathrm{h}(70 \mathrm{mph})$. During the weekday visits the off-peak service frequency was one train an hour. Figure 1(a) shows the localised wet spot area on the left-hand track as a lighter region caused by the drying of clay pumped to the surface. Figure 1 (a) Wet bed prior to track renewal. 1 (b) Close-up of worst region - slurry and pea gravel also visible. Arrows show direction of travel on affected line.
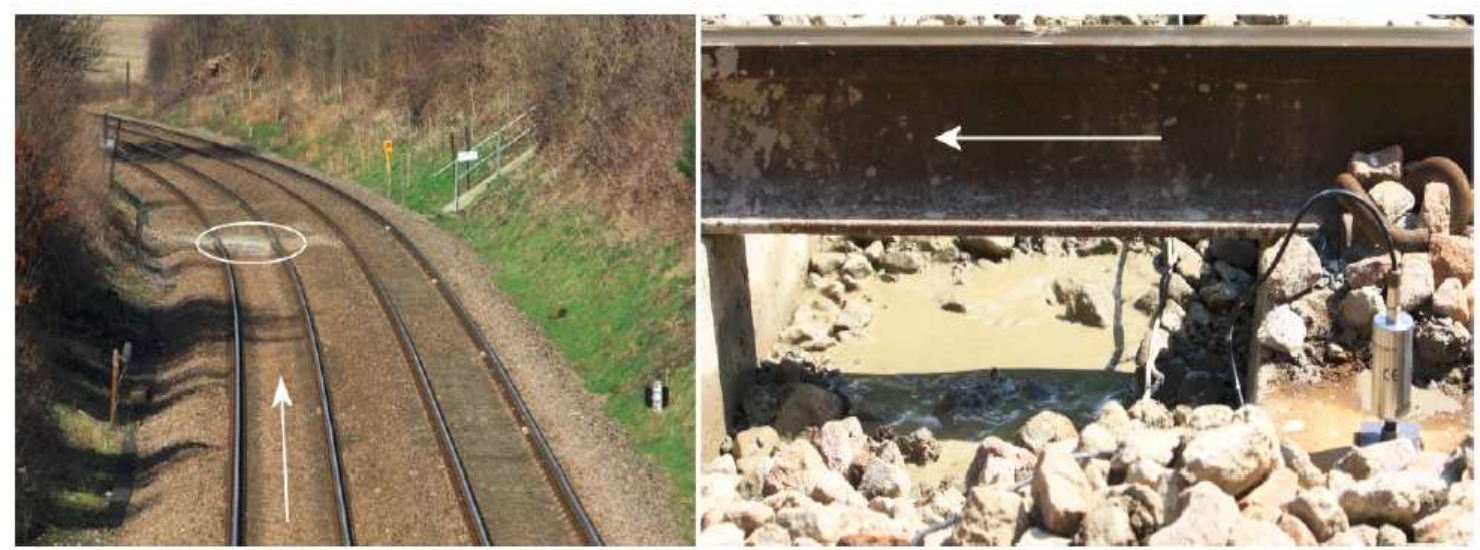

Figure 1. Photos prior to remediation (a) Site is circled (b) Close- up of worst region 
The wet spot lies roughly in the middle of a cutting with the local terrain rising to a high of 4 $\mathrm{m}$ above the track at the wet spot location.

It is possible that a contributing factor for the development of the wet spot is water runoff from the surrounding higher ground ponding on top of the underlying clay, along this section of track. The underlying geology is alluvial clay, silt, sand and gravel overlying mudstone of the Weald Clay formation.

Several previous attempts to remediate the problem were evident when the site was first visited from the condition of the wet spot and heaps of fouled ballast piled adjacent to the track. These had consisted of local ballast removal and repacking beneath the voided sleepers with chippings or pea gravel. Prior to renewal, Network Rail described the stretch of track which includes the wet bed, as "very poor" with a depth of the ballast was not known. Over a stretch of about $135 \mathrm{~m}$ which spanned the wet bed area, a micro-porous filter (TRACKTEX) sandwiched between geotextile (Tensar SSLA30) layers was used to separate the subgrade and fouled sub-ballast from the ballast. This is a type of renewal that, while relatively extensive falls short of a complete replacement of the track bed and omits the placement of a sub - ballast layer (sand blanket). Trackside measurements were taken prior to, immediately after and 5 months after renewal to determine the efficacy of the renewal in eliminating the recurrence of the wet spot.

During the renewal, a micro-porous geotextile filter was placed below $200 \mathrm{~mm}$ of new ballast. The use of the geotextile filter was intended to prevent future mud pumping by diverting water away from the subgrade and preventing subgrade material migrating upwards. However, its use in this context does not conform with accepted filter design practice, in that the transition from clay sized particles to ballast sized particles is not graded through suitably small steps. Although the geotextile filter saves the cost of a sand blanket, there is a risk that it may be ineffective. It is also normal practice during renewal to locally dig out and replace any very poor-quality subgrade material; and it is likely that, in the region of the wet spot, local excavation and replacement of material extended deeper than $200 \mathrm{~mm}$. To ensure that the same location was monitored after renewal, markers were identified on the adjacent, unrenewed line. The sleepers were slightly closer together after renewal, but the overall lengths monitored remained similar (sleeper 1 to 7 was $8.14 \mathrm{~m}$ pre-renewal and $7.83 \mathrm{~m}$ after renewal). Figure 4 shows a weld next to sleeper 3 . This could have been a potential trigger for the development of the wet spot.

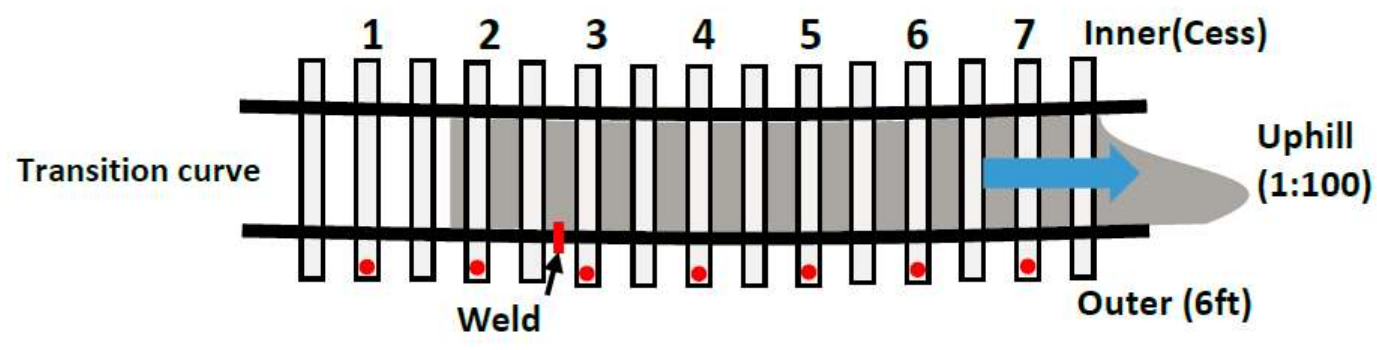


Figure 4. Site layout prior to renewal showing the approximate extent of the wet spot (in grey) and the vertical geophone locations (red circles). The arrow indicates the direction of travel.

However, it was noted that welds were present on the adjacent track where no wet bed was present. Thus, although the weld could have been partly responsible for the development of the wet bed, there is no proof of this.

Results

Figure 3 shows the ranges of movement of the instrumented sleepers. The largest movements (at sleepers 2, 3 and 4 prior to renewal) were between 2.5 and $4.0 \mathrm{~mm}$, indicative of soft support conditions. After renewal the movements reduced to between 0.5 and $1.0 \mathrm{~mm}$, indicative of well supported track. There was also much less variation in movement between sleepers.
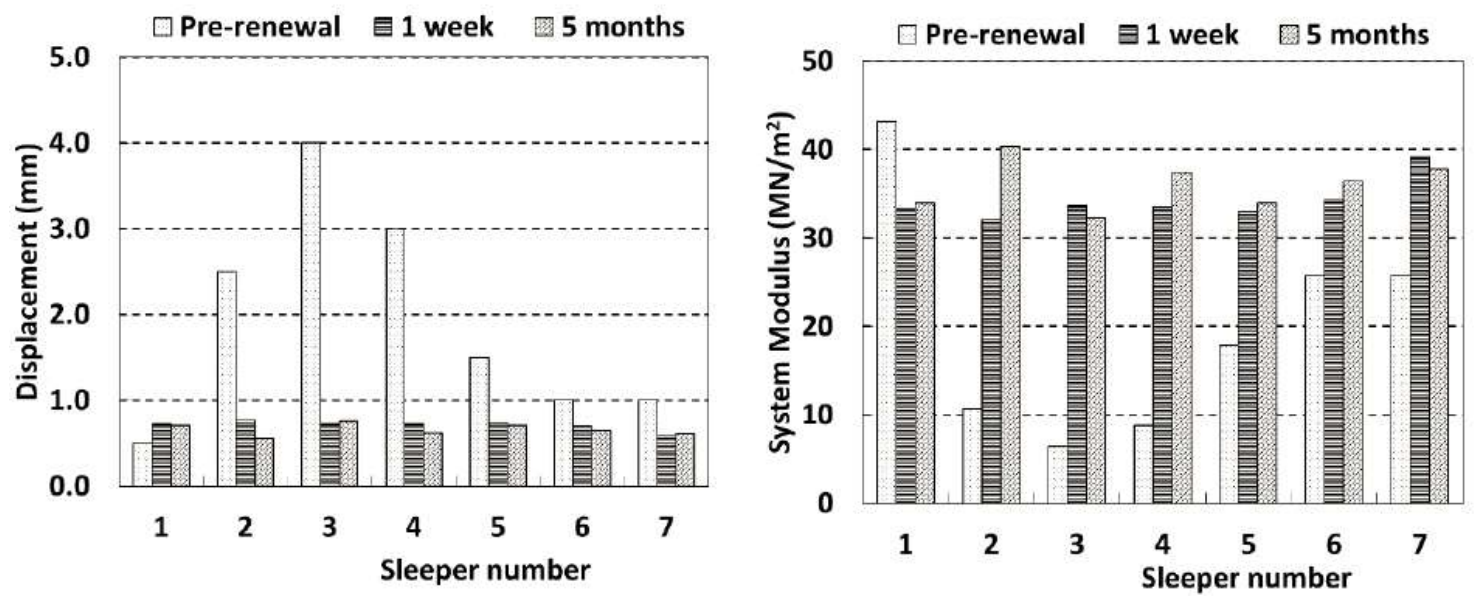

Figure 3. Class 171 (a) Average sleeper vertical deflection (b) Support system modulus

Conclusions

Measurements presented and evaluated have shown that of the two remediation methods applied, the repeated localised digging out and re-packing with chippings pea/gravel had been ineffective whereas the renewal appears to have resolved the problems at this site, at least over the period of monitoring. Measurements will continue to be made to determine the longterm effectiveness of the renewal in remediating the mud pumping issues at this site.

Conclusion and discussion

If geotextiles are correctly installed above the subgrade and meet the specification, they will demonstrate satisfactory performance and be cost effective. However, following systematic criteria in selecting geotextiles prior its installation is essential to ensure there are appropriate effects of geotextile's characteristics on the filtration system. The results of this research on turn indicate that thickness of granular filters can be significantly reduced by introducing 
suitable geotextile on the track system. The outcomes of this investigation emphasise the importance of providing a geotextile layer to the sub- ballast system through its economic role, in reducing the cost of the filter soil, and its efficiency, by increasing the permeability of the filtration layer (Fatahi et al. 2011).

Reinforced GRAFT tests demonstrated that XiTRACK reinforcement improved the stiffness of reinforced track with the same subgrade modulus and applied load by between 55 and $65 \%$ as well as reducing track settlement by around $99 \%$ after 500, 000 cycles of 44.4 tonne axle load on soft underlying subsoil. The XiTRACK sample remained fully free draining at the end of the test and show no signs of fatigue (pp266 - 267).Another study done at Herriot Watt University using the same GRAFT I facilities described that, the significant inflow of water during the in - situ site treatment during application demonstrates the need to perform track drainage enhancements at these types of difficult sites prior to any track bed construction bed improvements. It also showed a marked increase in track stiffness when the polymer was applied and the improvement was around $40 \%$ for the particular polymer (Woodward et al., 2014).

Geocell reinforcement did not perform well in GRAFT. When compared to unreinforced track with the same subgrade modulus and applied load it was found that geocell reinforcement increased track settlement by $37 \%$ and reduced track stiffness by 5 to $7 \%$ after 10, 000 cycles of 25 tonne axle load on a stiff clay subgrade (Kennedy 2011).

\section{Considered options}

\section{Concrete foundation slab and/or track}

Due to cyclic loads from trains and tide movements, water pressures can build up beneath a concrete slab. As a result, drainage beneath the slab would require special attention. This type of in situ solution was unachievable due to the concrete's cure pace, as track downtime would be too extensive. To minimize cracking on a concrete slab track, the subgrade would most likely need to be stabilized with cement or lime. Because extra track maintenance after track construction would be incredibly onerous, the solution would need to ensure that the track was completely maintenance free. Furthermore, there could be substantial transition issues from the soft clay track to the concrete-treated track.

\section{Concrete piles}

Using a vibrio poker, concrete columns are created all the way down to bedrock or a stronger stratum. To build the new track formation, a geo-mattress (transfer platform) is laid over the piles. The advantage of this system is that track stresses are transmitted to the stronger stratum; nevertheless, pile construction would be expensive and time-consuming. Furthermore, the construction of a hard point would be likely, and major track changes on both sides of the crossing would be required. This would very certainly entail customizing the heaps for the transition, raising costs and reducing track downtime. This approach was the recommended solution before XiTRACK was examined at Purfleet. 


\section{XiTRACK reinforcement}

XiTRACK is a patented method for greatly improving the qualities of ballast in order to create a "halfway house" between traditional ballasted track and concrete slab track. By producing a flexible but very durable geocomposite across the formation, the approach improves the load-distributing qualities of the ballast, greatly lowering long-term settlements at high-loading places. Because of the polymer's properties, it may be created without leaving a hard area, which is common when employing concrete solutions. Because the polymer is viscoelastic, it has excellent hysteretic damping characteristics. The treated and non-treated portions have good granular interlocking, leading in high levels of ballast integrity and stability. After treatment, drainage within the ballast is still maintained.

Normally, the polymer is applied to the ballast's surface in a certain pattern. The polymer cures as it enters the ballast, forming a three-dimensional geocomposite reinforcing cage. Although there will be some adherence to the ballast in dry conditions, the polymer's primary job is to construct this reinforcing cage. The method can be thought of as forming a geogrid at each level of the ballast in all three orthogonal directions, which is then linked together to generate a three-dimensional geo-matrix. Polymer penetration is controlled by altering the rheology of the polymer. The method is also said to include a built-in safety system, with the track reverting to a ballast state in the event of a polymer or geocomposite failure. However, it is recommended that the system be designed in such a way that maintenance can be performed at any time. Some remedies merely require a reduction in general maintenance; this may be the case with issues like transitions on and off directly anchored bridges, where embankment consolidation is still occurring.

Monitoring from track recording vehicles over previously treated sites has shown that the procedure will increase the track's capacity to keep its geometry significantly. Many of the sites were considered unmaintainable before the polymer was put (i.e. previous renewals had failed to maintain the track geometry).

\begin{tabular}{|l|l|l|l|l|l|}
\hline $\begin{array}{l}\text { Case } \\
\text { study }\end{array}$ & $\begin{array}{l}\text { Nature of the } \\
\text { problem }\end{array}$ & $\begin{array}{l}\text { Remediation } \\
\text { implemented }\end{array}$ & Advantages & $\begin{array}{l}\text { Potential } \\
\text { remedies }\end{array}$ & Disadvantages \\
\hline
\end{tabular}




\begin{tabular}{|c|c|c|c|c|c|}
\hline $\begin{array}{l}\text { No } 1 . \\
\text { The } \\
\text { Warf } \\
\text { level } \\
\text { crossing } \\
\text { Purfleet, } \\
\text { UK }\end{array}$ & $\begin{array}{l}\text { Bearing } \\
\text { failure; } \\
\text { excessive } \\
\text { plastic } \\
\text { deformation; } \\
\text { Weak } \\
\text { alluvial soil } \\
\text { and silts; } \\
\text { increased } \\
\text { usage }\end{array}$ & $\begin{array}{l}\text { Geotextile } \\
\text { separator; } \\
\text { XiTRACK } \\
\text { (Polyurethane } \\
\text { Ballast } \\
\text { Reinforcement } \\
\text { ) }\end{array}$ & $\begin{array}{l}\text { Preventing } \\
\text { migration of } \\
\text { fines into } \\
\text { ballast; } \\
\text { Regulating/ } \\
\text { increasing } \\
\text { ballast } \\
\text { stiffness/ } \\
\text { strength; } \\
\text { Remaining } \\
\text { free draining; } \\
\text { quick/ cost } \\
\text { effective; }\end{array}$ & $\begin{array}{l}\text { Concrete } \\
\text { foundation } \\
\text { slab/ track; } \\
\text { Concrete piles }\end{array}$ & $\begin{array}{l}\text { Increase cost/ } \\
\text { time; }\end{array}$ \\
\hline $\begin{array}{l}\text { No } 2 . \\
\text { Gravel } \\
\text { Hole, } \\
\text { UK }\end{array}$ & $\begin{array}{l}\text { Large track } \\
\text { displacement } \\
\text {. }\end{array}$ & $\begin{array}{l}\text { Micro piles } \\
\text { with enlarged } \\
\text { caps were } \\
\text { placed in the } \\
\text { cribs. }\end{array}$ & $\begin{array}{l}\text { Improve the } \\
\text { stiffness of the } \\
\text { subgrade as } \\
\text { well as where } \\
\text { are critical } \\
\text { velocity } \\
\text { locations and } \\
\text { embankment } \\
\text { instability } \\
\text { problems. }\end{array}$ & $\begin{array}{l}\text { Polyurethane } \\
\text { Ballast } \\
\text { Reinforcement }\end{array}$ & \\
\hline $\begin{array}{l}\text { No } 3 . \\
\text { The } \\
\text { Monk's } \\
\text { Lane, } \\
\text { UK }\end{array}$ & $\begin{array}{l}\text { Wet spots; } \\
\text { mud } \\
\text { pumping on } \\
\text { a ballast; } \\
\text { formation } \\
\text { problems; } \\
\text { Locally too } \\
\text { soft }\end{array}$ & $\begin{array}{l}\text { Replacement } \\
\text { of the track; } \\
\text { A micro- } \\
\text { porous filter } \\
\text { sandwiched } \\
\text { between } \\
\text { geotextile } \\
\text { layers }\end{array}$ & $\begin{array}{l}\text { Geosynthetic } \\
\text { filter and/or } \\
\text { sand-blanket } \\
\text { to prevent } \\
\text { ballast fouling } \\
\text { from below. }\end{array}$ & $\begin{array}{l}\text { Local } \\
\text { specification } \\
\text { of additional } \\
\text { compliant } \\
\text { layer e.g. } \\
\text { under sleeper } \\
\text { pads or under } \\
\text { ballast mats. } \\
\text { Improve } \\
\text { drainage. } \\
\text { Polyurethane } \\
\text { Ballast } \\
\text { Reinforcement }\end{array}$ & $\begin{array}{l}\text { Under sleeper } \\
\text { pads are not } \\
\text { always } \\
\text { effective. }\end{array}$ \\
\hline
\end{tabular}

A comparison of alternative proposed solutions, such as concrete foundations and/or piles, revealed the cost-effectiveness of the reinforcement method: in particular, the system's quick installation (the polymer dried in 15 seconds) reduced track downtime and thus provided significant cost savings. The design method was utilized to forecast track behavior before and after treatment, allowing the most appropriate polymer rheology, polymer distribution, and loading levels to be designed in order to achieve optimum performance and confirm that the procedure worked. The study done at Purfleet utilizing the approach is described in this paper, which includes recorded acceleration time records before and after treatment. The crossing was to be closed as little as possible to avoid financial damage to the container port and to avoid financial penalties imposed on Network Rail by train operators due to the lack of 
track access. Both the railway operating companies (TOCs) and the freight operating companies would have enforced these penalties (FOCs).

Ballast migration under high-speed loading regimes is a problem that current technologies can't solve. However, the application of in-situ polyurethane polymers, known as XiTRACK, has been widely utilized to stabilize and reinforce ballasted railway tracks in the UK and now increasingly internationally (Woodward et al., 2012). This method can be utilized to tackle these types of long-standing problems by displaying actual polymer application profiles at a typical important location. To equal out track stiffness fluctuations, softer rail pads on the firm side have frequently been suggested. However, ballast consolidation issues can still exist (the ballast in the transition zone will settle like any plain - line ballast), resulting in a difference in elevation between the stiff and weak sides, creating the circumstances for track fault formation (Woodward et al., 2012). Studies have also discovered that increasing the stiffness and strength of the track subgrade does not always increase transition performance since ballast movement still occurs (Li and Davis, 2005). It was discovered that none of these solutions improved transition performance, and that the majority of transition issues were caused by ballast movement. As a result, enhancing the ballast stiffness and strength utilizing an in-situ reinforcement technology that can fully stabilize the ballast geo- matrix should have a significant positive impact on the transition's performance (Woodward et al., 2012).

\section{REFERENCES}

1. Abadi T. (2015). Effect of Sleeper and Ballast Interventions on Rail Track Performance. PhD Thesis, University of Southampton. https://eprints.soton.ac.uk/388080/2/TA-final-thesis.pdf

2. Hudson A., Watson G., Pen L. and Powrie W. (2016). Remediation of Mud Pumping on a Ballasted Railway Track. Procedia Engineering Volume 143, pp 1043 - 1050. https://core.ac.uk/download/pdf/82293991.pdf 
3. MOD UK Railways Permanent Way Design and Maintenance (2009). Policy and Standards, Issue 4, Ministry of Defence, the Defence Movements and Transport Policy Division. https://assets.publishing.service.gov.uk/government/uploads/system/uploads/attach ment_data/file/565742/MOD_UK_Railway_Permanent_Way_Design and_Mainten ance_-issue 4.pdf

4. Statista, report available: https://www.statista.com/statistics/304957/total-historicalnational-rail-passenger-journeys-in-the-united-kingdom-uk/\#statisticContainer. (Last accessed 17 June 2021.)

5. Williams Rail Review 2021. Great British Railways. The Williams- Shapps Plan for Rail.https://assets.publishing.service.gov.uk/government/uploads/system/uploads/att achment_data/file/994603/gbr-williams-shapps-plan-for-rail.pdf.

6. Ebrahimi A., Tinjum J. and Edil T. (2012). Protocol for Testing Fouled Railway Ballast in Large- Scale Cyclic Triaxial Equipment. Geotechnical Testing Journal, Vol. 35, No. 5. https://www.researchgate.net/profile/TuncerEdil/publication/270544314_Protocol for Testing_Fouled_Railway_Ballast in_La rge-Scale_Cyclic Triaxial_Equipment/links/562f676308aea5dba8d35192/Protocolfor-Testing-Fouled-Railway-Ballast-in-Large-Scale-Cyclic-TriaxialEquipment.pdf? origin=publication detail

7. Ghataora G. (2017). Geotechnical Engineering for High Speed Rail. Permanent Way Institution.

https://www.thepwi.org/technical hub/presentations for tech hub/171019 high sp eed rail lines tech challenges/04 171019 high speed rail lines tech challenges ghataora

8. Cope G. and Ellis J. (1993). British Railway Track $6^{\text {th }}$ Edition, p.456-466.

9. Track System Requirements GC/RT5021 (2011). RSSB Railway Group Standard Issue 5 https://fdocuments.in/reader/full/track-system-requirements-rssb-iss5pdfpage-2-of-49-rssb-railway-group-standard

Esveld C. (2001). Modern Railway Track. Second Edition. http://www.esveld.com/Documents/MRT_Selection.pdf 
10. Ghataora, G., Burns, B., Burrow, M. and Evdorides, H., (2006) Development of an index test for assessing anti- pumping material in railway track foundations. Paper presented at the Proceedings of the First International Conference on Railway Foundations, Railfound06, University of Birmingham.

11. Ghataora, G. (2009). Research into the geotechnics of railway track foundations. Railway strategic. Issue no 278.

12. Wang, D., Sanchez, J.L., Briaud, M. (2014). Transportation Geotechnics, Vol. 1, Issue 4, Pages 257- 274.

13. Trinh, V. N., Tang, A. M., Cui, Y., Dupla, J., Canou, J., Calon, N., Lambert, L., Robinet, A. and Schoen, O. (2012). Mechanical characterisation of the fouled ballast in ancient railway track substructure by large-scale triaxial tests. Soils and Foundations, 52, p511-523.

14. Powrie W. and Le Pen L. (2016). A Guide to Track Stiffness. The Cross-Industry Track Stiffness Working Group, University of Southampton, UK. https://www.thepwi.org/technical hub/technical hub_files/a guide to track_stiffne ss final reviewr11

15. Cui, Y.J., Duong, T., Tang, A., Dupla, J., Calon, N. and Robinet, A. (2013). Investigation of the hydro-mechanical behaviour of fouled ballast. Journal of Zhejiang University Science A, 14, p244-255.

16. Duong, T. V., Tang, A. M., Cui, Y., Trinh, V. N., Dupla, J., Calon, N., Canou, J. and Robinet, A. (2013). Effects of fines and water contents on the mechanical behaviour of interlayer soil in ancient railway sub-structure. Soils and Foundations, 53, p868-878.

17. Duley, A., Le Pen, L., Thompson, D., Powrie, W., Watson, G.V.R., Musgrave, P., Cornish, A. (2014). Modelling and measurements of critical train speed effects and associated track movements. Proc International Conference on High Speed Rail, 8th-10th December 2014 Birmingham, UK. Available online: http://eprints.soton.ac.uk/381370/

18. Woodward P.K., Thompson D. and Banimahd M. (2007). Geocomposite technology: reducing railway maintenance. Proceedings of the Institution of Civil 
Engineers, Transport 160, p109- 115.

https://www.icevirtuallibrary.com/doi/pdf/10.1680/tran.2007.160.3.109 